\title{
Microphysical Characteristics of Three Convective Events with Intense Rainfall Observed by Polarimetric Radar and Disdrometer in Eastern China
}

\author{
Gang Chen ${ }^{1,2}\left(\right.$, Kun Zhao ${ }^{1,2, *}$, Long Wen ${ }^{1}\left(\mathbb{0}\right.$, Mengyao Wang ${ }^{1}$, Hao Huang ${ }^{1}{ }^{1}$, \\ Mingjun Wang ${ }^{1}$, Zhengwei Yang ${ }^{1}$, Guifu Zhang ${ }^{1,3} \mathbb{D}$, Pengfei Zhang ${ }^{3,4}$ and Wen-Chau Lee ${ }^{5}$ \\ 1 Key Laboratory for Mesoscale Severe Weather/MOE and School of Atmospheric Science, Nanjing University, \\ Nanjing 210003, China \\ 2 State Key Laboratory of Severe Weather and Joint Center for Atmospheric Radar Research of CMA/NJU, \\ Beijing 100081, China \\ 3 School of Meteorology and Advanced Radar Research Center, University of Oklahoma, \\ Norman, OK 73072, USA \\ 4 NOAA/National Severe Storms Laboratory, Norman, OK 73072, USA \\ 5 National Center for Atmospheric Research\#, Boulder, CO 80305, USA \\ * Correspondence: zhaokun@nju.edu.cn; Tel.: +86-0258-968-2539
}

Received: 23 July 2019; Accepted: 22 August 2019; Published: 24 August 2019

\begin{abstract}
Polarimetric radar and disdrometer observations obtained during the 2014 Observation, Prediction, and Analysis of Severe Convection of China (OPACC) field campaign are used in this study to investigate the microphysical characteristics of three primary types of organized intense rainfall events (meiyu rainband, typhoon outer rainband, and squall line) in eastern China. Drop size distributions (DSDs) of these three events on the ground are derived from measurements of a surface disdrometer, while the corresponding three-dimensional microphysical structures are obtained from the Nanjing University C-band polarimetric radar (NJU-CPOL). Although the environmental moisture and instability conditions are different, all three events possess relatively high freezing level favorable for warm-rain processes where the high medium to small raindrop concentration at low levels is consistent with the high surface rainfall rates. Convection is tallest in the squall line where abundant ice-phase processes generate large amounts of rimed particles (graupel and hail) above the freezing level and the largest surface raindrops are present among these three events. The storm tops of both the typhoon and meiyu rainbands are lower than that in the squall line, composed of less active ice processes above the freezing level. The typhoon rainrate is more intense than that of meiyu, enhanced by higher coalescence efficiency. A revised generalized intercept parameter versus mass-weighted mean diameter $\left(\mathrm{N}_{\mathrm{w}}-\mathrm{D}_{\mathrm{m}}\right)$ space diagram is constructed to describe the DSD distributions over the three events and illustrate the relative DSD positions for heavy precipitation. DSDs of these intense rainfall convections observed in this midlatitude region of eastern Asia somewhat represent the typical DSD characteristics in low latitudes, suggesting that the parameterization of microphysical characteristics in eastern China in numerical models needs to be further investigated to improve rain fall forecasts in these heavy rainfall events.
\end{abstract}

Keywords: microphysical characteristics; convective events; intense rainfall; eastern China

\section{Introduction}

Rainfall from convective systems accounts for a significant portion of the total precipitation during the monsoon season in eastern China [1,2]. Flash floods associated with these extreme precipitation events occur frequently in eastern China, causing severe damage to properties and loss of lives. To improve 
quantitative precipitation forecast (QPF) skills for these convection systems, better understanding of precipitation structures and microphysical characteristics is essential to improve physical and microphysical representations in numerical weather prediction models. For example, different microphysics schemes in the Weather Research and Forecasting (WRF) model perform differently in certain rainfall events [3-5], which is mainly related to the different representations of microphysical processes. Therefore, observations of the microphysical characteristics in precipitation systems are crucial toward refining microphysics schemes in numerical models and ultimately improving QPF.

Rainfall drop size distributions (DSDs) can be obtained from disdrometer observations [6-8]. The three-dimensional precipitation structures, particularly the vertical structures associated with the evolution of microphysical processes and hydrometeor distributions, are mainly inferred through polarimetric radar observations [9-11]. Observations from disdrometers in conjunction with polarimetric radars have been commonly used for investigating DSDs and precipitation structures in different climate regimes [12-15]. The combined analyses have also provided insights into the microphysical structures of certain precipitation cases (e.g., squall lines, typhoon rainbands, etc.) in eastern China $[16,17]$. However, the quantitative comparison of observed microphysical characteristics among these summertime convection systems which commonly bring heavy precipitation amounts have yet to be discussed in detail.

The microphysical characteristics of convective clusters were first classified into maritime and continental types [12]. Subsequent studies revealed that the variation of environmental conditions, in addition to geographic locations, also affects the microphysical properties of convective systems. The precipitation in warmer and more humid maritime (drier continental) environments is mainly composed of raindrops with higher (lower) number concentration and smaller (bigger) mean drop size [2,14,18-20]. Recently, Dolan et al. [15] (hereafter, DO18) classified the global DSD characteristics into six groups based on the principal component analysis to twelve disdrometer datasets (Supplementary Materials) across three latitude bands on Earth. In their study, a typical clustering of DSDs (group 5) as the signature of robust warm-rain processes (high rain rate, large number concentration, and moderate mean size) was shown in the low latitudes but rarely emerged in the midlatitudes. On the other hand, another distinct group of DSDs (group 6) associated with ice-based convection (large mean drop size but small number concentration), was frequently emerged in the midlatitudes. It indicated that the distribution of DSDs vary in different latitudes, and the two DSD groups above seem to be helpful to distinguish the DSD characteristics of the midlatitudes from the low latitudes.

During the 2014 Observation, Prediction, and Analysis of Severe Convection of China (OPACC) field campaign in eastern China (in the midlatitude of Asian monsoon region) [16], several precipitation events were captured by multiple instruments. Three heavy precipitation events [meiyu rainband (meiyu), typhoon outer rainband (typhoon) over land, and squall line], were observed and selected for the study. The cases belong to three primary types of convective systems which produce the majority of extreme rainfall events in China [21]. Chen et al. [22] has documented the radar quantitative precipitation estimation (QPE) performances of the three events, the effects of microphysical features on the radar QPE results near surface has also been discussed. This study expands their work to compare the microphysical features among the three precipitation events, for a better understanding of the similarity and differences of microphysical characteristics in these three types of intense convective systems in eastern China. The variation of DSD characteristics for these heavy precipitation events occurring is also summarized.

This paper is organized as follows: data and methodology are introduced in Section 2. The results are described in Section 3. The microphysical characteristics are discussed in Section 4, and the conclusions are given in Section 5.

\section{Data and Methodology}

\subsection{The NJU-CPOL Radar and Disdrometer}

The radar data were collected from the Nanjing University C-band polarimetric radar (NJU-CPOL) during the OPACC in summer 2014. The data quality control (QC) procedures for the polarimetric radar 
variables are the same as in Chen et al. [22]. Firstly the system biases for the radar reflectivity $\left(Z_{\mathrm{H}}\right)$ and differential reflectivity $\left(Z_{\mathrm{DR}}\right)$ are calibrated using a metal sphere experiment and the vertically pointing data in light rain, respectively. After eliminating the non-meteorological echoes, an enhanced linear programming method [23] is used for the recalculation of the specific differential phase $\left(\mathrm{K}_{\mathrm{DP}}\right)$. Then the attenuation of $Z_{H}\left(Z_{D R}\right)$ are corrected based on the linear relation between the specific horizontal attenuation $\mathrm{A}_{\mathrm{H}}$ (the specific differential attenuation $\mathrm{A}_{\mathrm{DP}}$ ) and $\mathrm{K}_{\mathrm{DP}}$ [22]. After $\mathrm{QC}$, the radar data in each volume coverage pattern (VCP), consisting 14-elevation Plan Position Indicator (PPI) Scans, are interpolated onto constant altitude PPI (CAPPI) in a Cartesian grid using the NCAR REORDER software package with $1.0 \mathrm{~km}$ horizontal and $0.5 \mathrm{~km}$ vertical grid spacing starting from $0.5 \mathrm{~km}$ above ground level (AGL).

A second-generation OTT PARSIVEL disdrometer (OTT-2), located at ZhuangMu (ZM) station $\sim 20 \mathrm{~km}$ north of the NJU-CPOL, is used to collect DSDs. The OTT-2 measures 32 bins of diameter from 0 to $25 \mathrm{~mm}$ and 32 bins of fall speeds from 0 to $22.4 \mathrm{~m} \mathrm{~s}^{-1}$ [24]. The first two size bins (0.062 and $0.187 \mathrm{~mm}$ ) are not used because of the low signal-to-noise ratios and the smallest size starts at the third bin with $0.312 \mathrm{~mm}$ in diameter. Spurious drops larger than $8 \mathrm{~mm}$ or $40 \%$ above or below the fall velocity-diameter relationship are also eliminated, to remove the impact of wind or splash on the disdrometer measurements [25-27]. A size correction proposed by Battaglia et al. [28] has also been applied to the OTT-2 observations to minimize measurement errors. Raindrops below 1-mm equivalent sphere diameter are assumed to be spherical, where the ratio between the height and width (hereafter referring to axis ratio) is 1 . While the axis ratios are assumed to change linearly from 1 to 0.7 for the raindrops with diameters between 1 and $5 \mathrm{~mm}$. But for drops with diameters above $5 \mathrm{~mm}$, the axis ratio is constant and set to 0.7. Previous studies have found that the OTT PARSIVEL disdrometer would underestimate small raindrops and resulted in relatively higher $D_{m}$ and lower $\mathrm{N}_{\mathrm{W}}[29,30]$, which should be treated carefully when compared with the DSD results observed with other instruments, like two-dimensional video disdrometer (2DVD).

\subsection{Raindrop Size Distribution Parameters}

The integral rainfall parameters, including rain rate $\mathrm{R}\left(\mathrm{mm} \mathrm{h}^{-1}\right)$ and liquid water content (LWC, $\left.\left(\mathrm{g} \mathrm{m}^{-3}\right)\right)$, are computed from the disdrometer observed raindrop size distribution:

$$
\begin{gathered}
\mathrm{R}=\frac{6 \pi}{10^{4}} \sum_{\mathrm{i}=1}^{\mathrm{L}} \mathrm{D}_{\mathrm{i}}^{3} \mathrm{~V}_{\mathrm{i}} \mathrm{N}\left(\mathrm{D}_{\mathrm{i}}\right) \Delta \mathrm{D}_{\mathrm{i}}, \\
\mathrm{LWC}=\frac{\pi}{6000} \sum_{\mathrm{i}=1}^{\mathrm{L}} \mathrm{D}_{\mathrm{i}}^{3} \mathrm{~N}\left(\mathrm{D}_{\mathrm{i}}\right) \Delta \mathrm{D}_{\mathrm{i}},
\end{gathered}
$$

where $\mathrm{L}$ is the total number of bins (30) for the OTT-2, $\mathrm{D}_{\mathrm{i}}(\mathrm{mm})$ is the equivalent spherical raindrop diameter, $\Delta \mathrm{D}_{\mathrm{I}}$ is the corresponding diameter interval $(\mathrm{mm}), \mathrm{V}_{\mathrm{i}}\left(\mathrm{m} \mathrm{s}^{-1}\right)$ is the fall speed obtained with the theoretical formula from Brandes et al. [31], and $\mathrm{N}(I)\left(\mathrm{mm}^{-1} \mathrm{~m}^{-3}\right)$ represents the corresponding number concentration of raindrops for bin $\mathrm{I}$, respectively.

The nth-order moment of the DSDs can be expressed as:

$$
M_{n}=\int_{0}^{D_{\max }} D^{n^{n}} N(D) d D,
$$

where $D(\mathrm{~mm})$ represents the equivalent diameter and $N(D)\left(\mathrm{mm}^{-1} \mathrm{~m}^{-3}\right)$ is the number concentration of raindrops in a unit volume of air and unit size interval. The mass-weighted mean diameter $\mathrm{D}_{\mathrm{m}}(\mathrm{mm})$ equals the ratio of the fourth to the third moment of the size distribution:

$$
\mathrm{D}_{\mathrm{m}}=\frac{\mathrm{M}_{4}}{\mathrm{M}_{3}}
$$


and the generalized intercept parameter $N_{w}\left(m^{-1} m^{-3}\right)$ is computed as Bringi et al. [12]:

$$
\mathrm{N}_{\mathrm{w}}=\frac{4^{4}}{\pi \rho_{\mathrm{w}}}\left(\frac{10^{3} \mathrm{LWC}}{\mathrm{D}_{\mathrm{m}}^{4}}\right)
$$

where $\rho_{w}$ is the density of water $\left(1.0 \mathrm{~g} \mathrm{~cm}^{-3}\right)$.

\subsection{Hydrometeor Identification Algorithm (HID)}

The HID is a fuzzy-logic algorithm based on the construction of membership functions for each polarimetric variable to identify the hydrometeor type that dominates the radar resolution volume [32-35]. The NJU-CPOL HID follows Dolan et al. [34] that considers the unique scattering characteristics of $\mathrm{C}$-band polarimetric radar, such as the $\mathrm{C}$-band resonance effects when drops with diameters of 5.5-7 mm exist in the radar volume. Five variables including temperature, $Z_{\mathrm{H}}, Z_{\mathrm{DR}}$, correlation coefficient $\left(\rho_{h v}\right)$ and $\mathrm{K}_{\mathrm{DP}}$ are used to identify the hydrometeor types, temperature data is obtained from the Jiangning radiosonde located $\sim 170 \mathrm{~km}$ east of the NJU-CPOL. Membership beta functions are the same as in Dolan et al. [34]. Ten hydrometeor types are identified in the HID including: drizzle, rain, big drops, ice crystals, vertical aligned ice, aggregates, wet snow, high-density (HD) graupel, low-density (LD) graupel and hail. Limitations of fuzzy-logic based HID include: (1) it can only identify the dominant rather than all the hydrometeor types in one radar sample volume, and (2) the overlap of polarimetric boundaries among different hydrometeor types sometimes turns to erroneously identified particle species. Radar data quality can also limit the accuracy of the HID results [9]. However, it remains the most reliable method for the identification of hydrometeor types by polarimetric radars.

\subsection{Rain and Ice Water Content Estimation}

The method for estimating rain water content using polarimetric radar observations varies at different heights, which is similar to Chang et al. [36]. In the presence of mixed-phase precipitation, the difference reflectivity $\left(Z_{D P}, d B\right)$ method [37] is used to discriminate $Z_{H}$ for rain and ice. A $Z_{H}^{\text {rain }}-Z_{D P}$ relation is determined from two years of disdrometer data in eastern China:

$$
\mathrm{Z}_{\mathrm{H}}^{\mathrm{rain}}=0.0057 \mathrm{Z}_{\mathrm{DP}}^{2}+0.477 \mathrm{Z}_{\mathrm{DP}}+17.86 \text {. }
$$

Then $\mathrm{M}_{\mathrm{w}}$ and $\mathrm{M}_{\mathrm{i}}$, which represent the total mass of liquid and solid hydrometeors in the radar resolution volume, are estimated using the reflectivity-water content (Z-M) relationships adopted from previous studies [16,36,37]:

$$
\mathrm{M}_{\mathrm{w}}=3.44 \times 10^{-3}\left(\mathrm{Z}_{\mathrm{h}}^{\text {rain }}\right)^{4 / 7}\left(\mathrm{~g} \mathrm{~m}^{-3}\right),
$$

and

$$
\mathrm{M}_{\mathrm{i}}=1000 \pi \rho_{\mathrm{i}} \mathrm{N}_{0}^{3 / 7}\left(\frac{5.28 \times 10^{-18} \mathrm{Z}_{\mathrm{h}}^{\text {ice }}}{720}\right)^{4 / 7}\left(\mathrm{~g} \mathrm{~m}^{-3}\right),
$$

where $Z_{\mathrm{h}}^{\text {rain }}$ is the linear form of $Z_{\mathrm{H}}^{\text {rain }}$, and $\mathrm{Z}_{\mathrm{h}}^{\text {ice }}$ is calculated as follows:

$$
\mathrm{Z}_{\mathrm{h}}^{\text {ice }}=10^{\frac{\mathrm{Z}_{\mathrm{H}}}{10}}-\mathrm{Z}_{\mathrm{h}}^{\text {rain }}
$$

Values of negative $Z_{h}^{\text {ice }}$ can be obtained when the values of $Z_{H}$ and $Z_{D R}$ are high, it happens when the mean raindrop size is high and treated as pure rain. When only ice exists, the ice mass $\left(\mathrm{M}_{\mathrm{i}}\right)$ is directly estimated via (8). When in pure rain regions, the liquid water content $\left(\mathrm{M}_{\mathrm{W}}\right)$ is calculated from the C-G model retrieval method [38]. Discontinuity may exist between the C-G method and Z-M relationship, while more accurate liquid water content can be obtained by using two parameters $\left(Z_{\mathrm{H}}\right.$ and $Z_{\mathrm{DR}}$ ) from the $\mathrm{C}-\mathrm{G}$ method [36]. 


\section{Results}

\subsection{Environmental Conditions and OTT-2 Observations}

\subsubsection{Event Description and Environmental Conditions}

Three precipitation events (meiyu, typhoon, and squall line) observed by the NJU-CPOL and an OTT-2 during the OPACC field campaign in 2014 in eastern China are selected for the study. Time periods during the passages of the three convection events over the OTT-2 and corresponding radar scanning sequences are provided in Table 1 . The selected NJU-CPOL radar reflectivity CAPPIs at 2-km AGL are shown in Figure 1. The black arrows represent the moving directions for the three precipitation events, it indicates that the ZM OTT basically captured the main part of the three precipitation systems during their passage through this site. Values of $\mathrm{Z}_{\mathrm{H}}$ in the mature convective cells for the meiyu system are over $45 \mathrm{dBZ}$ when almost reaching the OTT-2 site around 11:50 local standard time (LST) (LST = $\mathrm{UTC}+8$ ) on $12 \mathrm{July}, 2014$. The maximum $\mathrm{Z}_{\mathrm{H}}$ for the typhoon rainband exceeds $50 \mathrm{dBZ}$ from 16:50 to 17:50 LST on 24 July, 2014, while it moved westward. As for the squall line, maximum radar reflectivity also exceeds $50 \mathrm{dBZ}$ when passing through the OTT-2 site at 20:30 LST on $30 \mathrm{July}, 2014$.
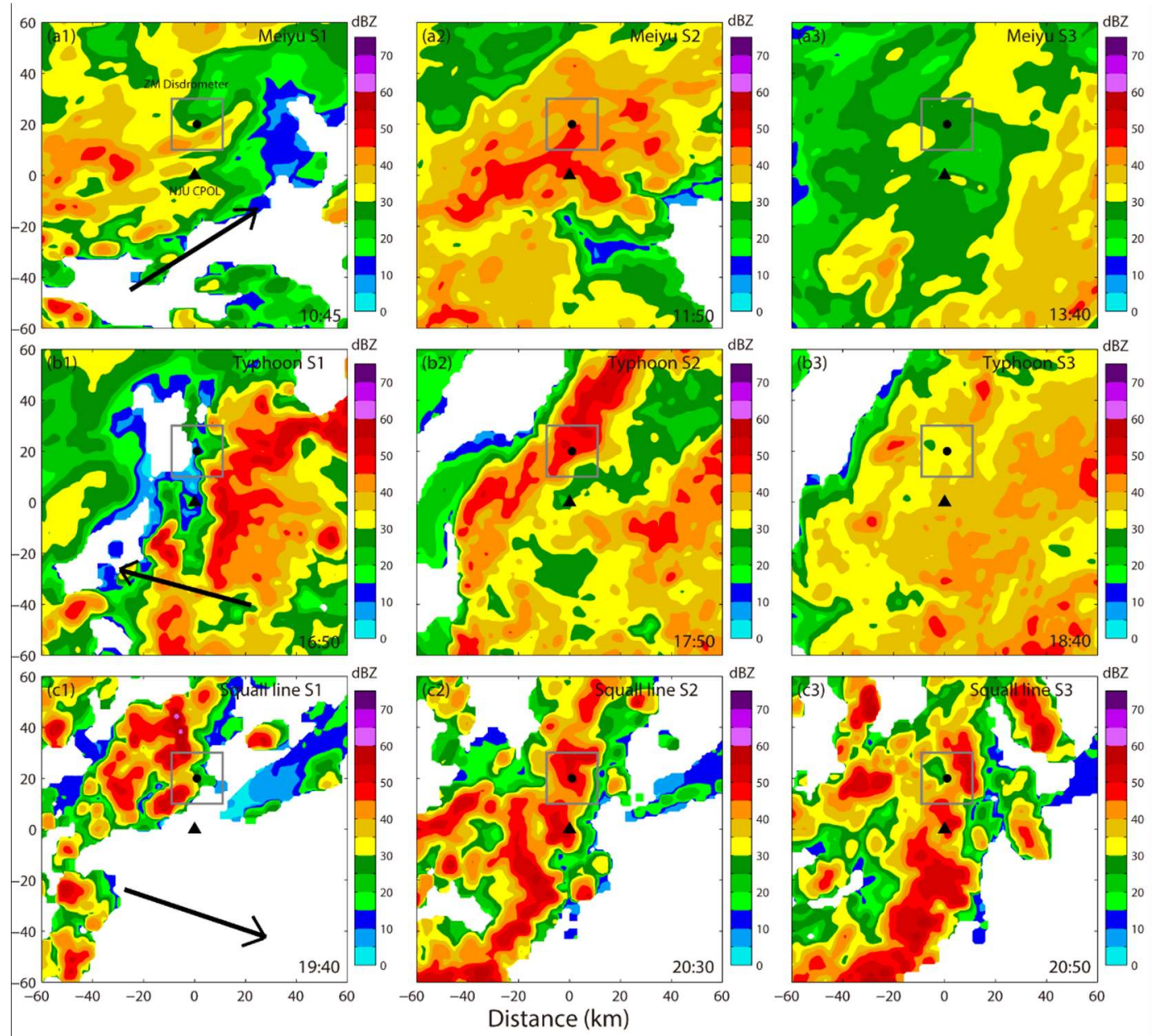

Figure 1. The selected constant altitude Plan Position Indicator (CAPPI) scans of radar reflectivity at 2-km AGL from the Nanjing University C-band polarimetric radar (NJU-CPOL) radar in (a) meiyu, (b) typhoon, and (c) squall line, respectively. The solid circle represents the location of the ZhuangMu (ZM) disdrometer, which is about $20 \mathrm{~km}$ to the NJU-CPOL (solid triangle). The moving directions of the three precipitation events are shown with black arrows. And the $20 \mathrm{~km} \times 20 \mathrm{~km}$ rectangle centered round the disdrometer is shown with the gray box. 
Table 1. Time periods for the analysis of the three weather systems.

\begin{tabular}{ccc}
\hline Weather Systems & Time (LST) & Radar Volume Coverage Pattern (VCPs) \\
\hline Meiyu & 12 July, 2014, 10:45-13:40 & 26 \\
Typhoon & 24 July, 2014, 17:00-18:40 & 14 \\
Squall line & 30 July, 2014 19:50-21:00 & 11 \\
\hline
\end{tabular}

The environmental conditions of these events are depicted by the skew T-logP diagrams from the Jiangning radiosonde (Figure 2). Several parameters to characterize the environment are presented in Table 2. The convective available potential energy (CAPE) for the squall line case is $\sim 3428 \mathrm{Jkg}^{-1}$, suggesting strong instability favorable for the development of deep convection [39]. In contrast, the CAPEs are modest in the meiyu $\left(940 \mathrm{Jkg}^{-1}\right)$ and typhoon rainband $\left(1404 \mathrm{Jkg}^{-1}\right)$ events, limiting the maximum updraft and vertical development of convection. The $0-6 \mathrm{~km}$ vertical wind shears are moderate for the three events $\left(13.9,13.5\right.$, and $11.6 \mathrm{~m} \mathrm{~s}^{-1}$ ) (Table 2), which are consistent with the organization of multicellular convection results in longer lifetime and larger rainfall accumulation when compared with single-cell convection [40,41]. As for the environment moisture, the air is almost saturated below $400 \mathrm{hPa}$ (the red line in Figure 2b) before the passage of the typhoon rainband and is accompanied by a mean relative humidity $\sim 91 \%$ between 0.5 and $3.5 \mathrm{~km}$. The environmental air is also moist at low levels in the meiyu event with a mean relative humidity between $0.5-3.5 \mathrm{~km}$, $\sim 84 \%$. For the squall line event, the relative humidity is $\sim 59 \%$ in the same vertical layer, suggesting the driest environment at low levels among these three events. Precipitable water (PW) from the surface to $300 \mathrm{hPa}$ is equivalent to the vertical accumulation of water vapor content, a good indicator of the environmental moisture field [42]. Values of PW (Table 2) indicate that the moist environments of the three events are suitable for the intense rainfall, especially for the typhoon case $(71.1 \mathrm{~mm})$. On the other hand, all three events possess low LCLs $(<1 \mathrm{~km})$ and high freezing levels $(>5 \mathrm{~km})$ (Table 2$)$. The presence of thick warm cloud layers $(>4 \mathrm{~km})$ are in favor of warm-rain processes [43].
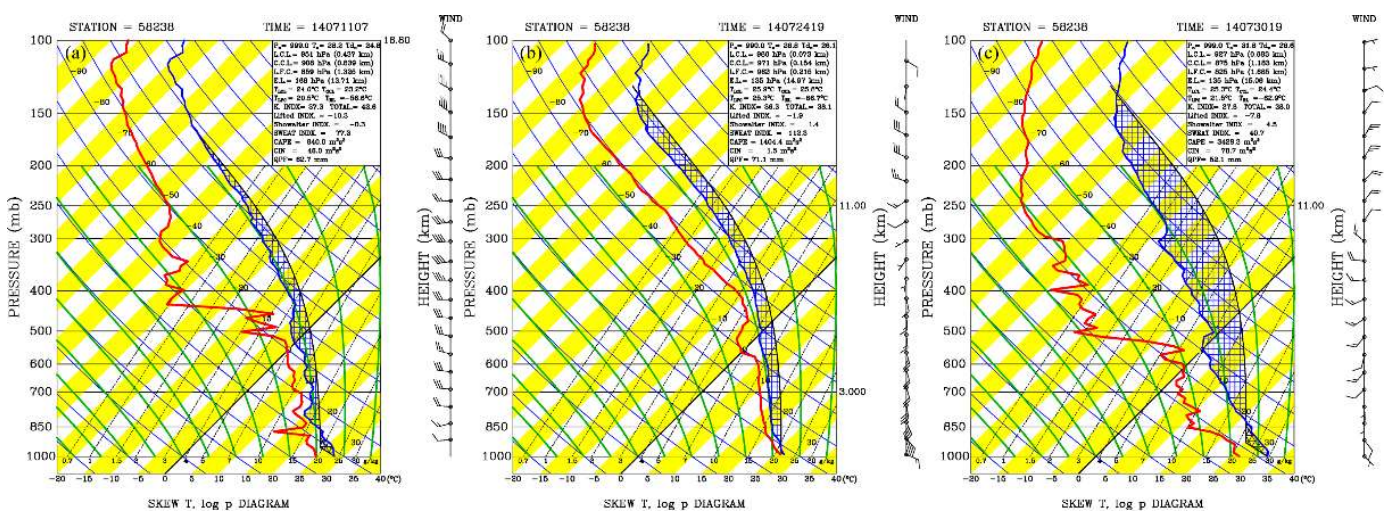

Figure 2. The skew T-LogP diagrams and vertical wind profiles of (a) meiyu, (b) typhoon, and (c) squall line from the Jiangning radiosonde. The black curve is the ascending path of a surface-based parcel, while the blue and red lines are temperature and dew point temperature profiles, respectively.

Table 2. Environment parameters obtained from radiosonde of the three systems.

\begin{tabular}{ccccccccc}
\hline $\begin{array}{c}\text { Weather } \\
\text { Systems }\end{array}$ & $\begin{array}{c}\text { CAPE } \\
\mathbf{( J k g}^{-1} \mathbf{)}\end{array}$ & $\begin{array}{c}\mathbf{0 - 6} \mathbf{~ k m} \\
\text { Shear } \\
\mathbf{( m s}^{-1} \mathbf{)}\end{array}$ & $\begin{array}{c}\mathbf{P W} \\
\mathbf{( m m )}\end{array}$ & $\begin{array}{c}\text { Relative } \\
\text { Humidity } \\
\mathbf{( 0 . 5 - 3 . 5} \mathbf{~ k m )}\end{array}$ & $\begin{array}{c}\text { LCL } \\
\mathbf{( k m )}\end{array}$ & $\begin{array}{c}\text { Freezing } \\
\text { Level } \\
\mathbf{( k m )}\end{array}$ & $\begin{array}{c}-\mathbf{1 0}{ }^{\circ} \mathbf{C} \\
\text { Level } \\
\mathbf{( k m )}\end{array}$ & $\begin{array}{c}-\mathbf{2 0}{ }^{\circ} \mathbf{C} \\
\text { Level } \\
(\mathbf{k m})\end{array}$ \\
\hline Meiyu & 940 & 13.9 & 62.7 & $84 \%$ & 0.4 & 5.3 & 7.4 & 8.9 \\
Typhoon & 1404 & 13.5 & 71.1 & $91 \%$ & 0.1 & 5.6 & 7.6 & 9.2 \\
Squall line & 3428 & 11.6 & 52.1 & $59 \%$ & 0.7 & 5.1 & 7.1 & 8.6 \\
\hline
\end{tabular}




\subsubsection{Evolution of Rainfall and Accompanied Drop Size Distributions}

The microphysical characteristics during the passage of the three convective systems over the OTT-2 are investigated using the DSD time series and the instantaneous rain rate derived from the 1-min OTT-2 observations (Figure 3). The convective and stratiform types of samples are classified with the method used in Bringi et al. [12] and illustrated by the red and black bars on the top of the diagram, respectively. For the typhoon and squall line (Figure $3 b, c)$, high concentrations $\left[\mathrm{N}(\mathrm{d}) \sim 10^{4} \mathrm{~m}^{-3} \mathrm{~mm}^{-1}\right]$ of small drops $(\mathrm{d}<1 \mathrm{~mm})$ are observed, while the concentration of medium drops $(\mathrm{d} \sim 1-3 \mathrm{~mm})$ reached $10^{3} \mathrm{~m}^{-3} \mathrm{~mm}^{-1}$ with a few large raindrops $(\mathrm{d}>3 \mathrm{~mm})$ recorded. The maximum instantaneous rain rates (pink lines) in these two systems exceeded $100 \mathrm{~mm} \mathrm{~h}^{-1}$, consistent with the high concentrations of small raindrops. Between these two systems, more large drops $(\mathrm{d}>3 \mathrm{~mm}$ ) are present in the squall line. On the other hand, fewer small and medium drops are observed in meiyu with almost no large raindrops measured, resulting in the lowest maximum instantaneous rain rate $\left(\mathrm{R} \sim 50 \mathrm{mmh}^{-1}\right)$ among the three systems.
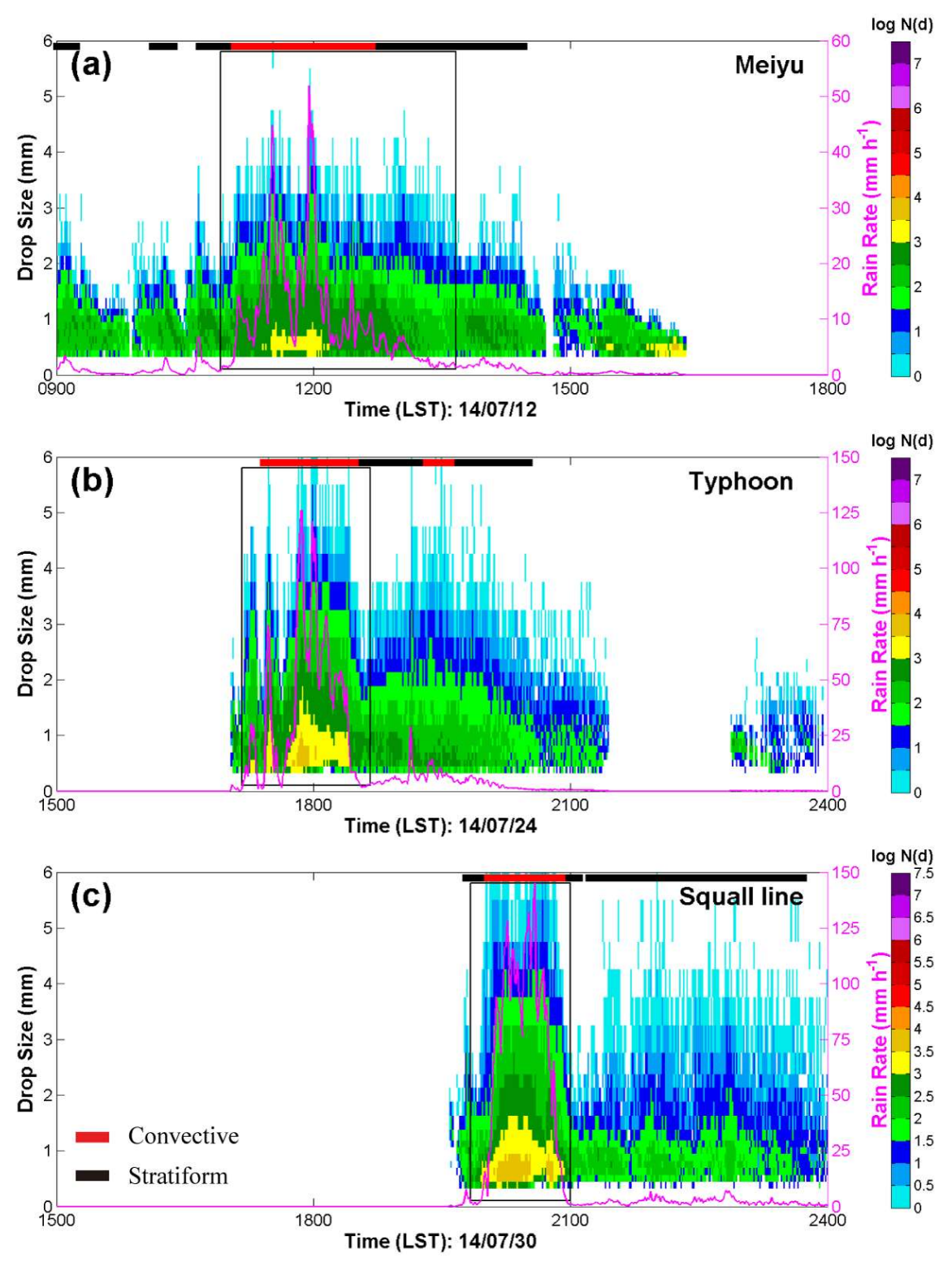

Figure 3. Time series of drop size distributions (DSDs) and rain rate calculated from ZM disdrometer in (a) meiyu, (b) typhoon, and (c) squall line. The color shading represents the DSD in logarithmic units of $\mathrm{mm}^{-1} \mathrm{~m}^{-3}$ and the $y$ axis on the left indicates the equivalent volume diameter $(\mathrm{mm})$ of raindrops, 
while the pink line represents the instantaneous rain rate $\left(\mathrm{mm} \mathrm{h}^{-1}\right)$ is consistent with y axis on right. The classified convective and stratiform samples are illustrated by the red and black bars on the top of the diagram, respectively. Black rectangles show the time periods for further analysis.

For further comparison of the surface DSDs among the three events, the DSD time series during the passage of precipitation systems are shown in Figure 4. For the meiyu event (Figure 4a), the instantaneous rain rate increases to the first peak at 11:25 and reaches the second peak at 11:55 (Figure 4a3) while $\mathrm{D}_{\mathrm{m}}$ increases from $1 \mathrm{~mm}$ to $2.3 \mathrm{~mm}$ (Figure 4a1) and the maximum value of LWC reaches $2 \mathrm{~g} \mathrm{~m}^{-3}$ (Figure 4a2). Values of $\log _{10} \mathrm{~N}_{\mathrm{w}} \sim 4$ and $\mathrm{D}_{\mathrm{m}} \sim 2.2 \mathrm{~mm}$ (Figure 4a1) when at the peak rain rate $\left(\mathrm{R} \sim 50 \mathrm{mmh}^{-1}\right)$, and their distributions fall between the maritime and continental convective clusters (gray rectangles) reported by Bringi et al. [12]. As the instantaneous rain rate decreases, LWC reduced to near zero and the distributions of $\mathrm{D}_{\mathrm{m}}$ and $\mathrm{N}_{\mathrm{w}}$ move toward the bottom left and pass through the black dashed stratiform rain types fitting line [12], into the stratiform region.
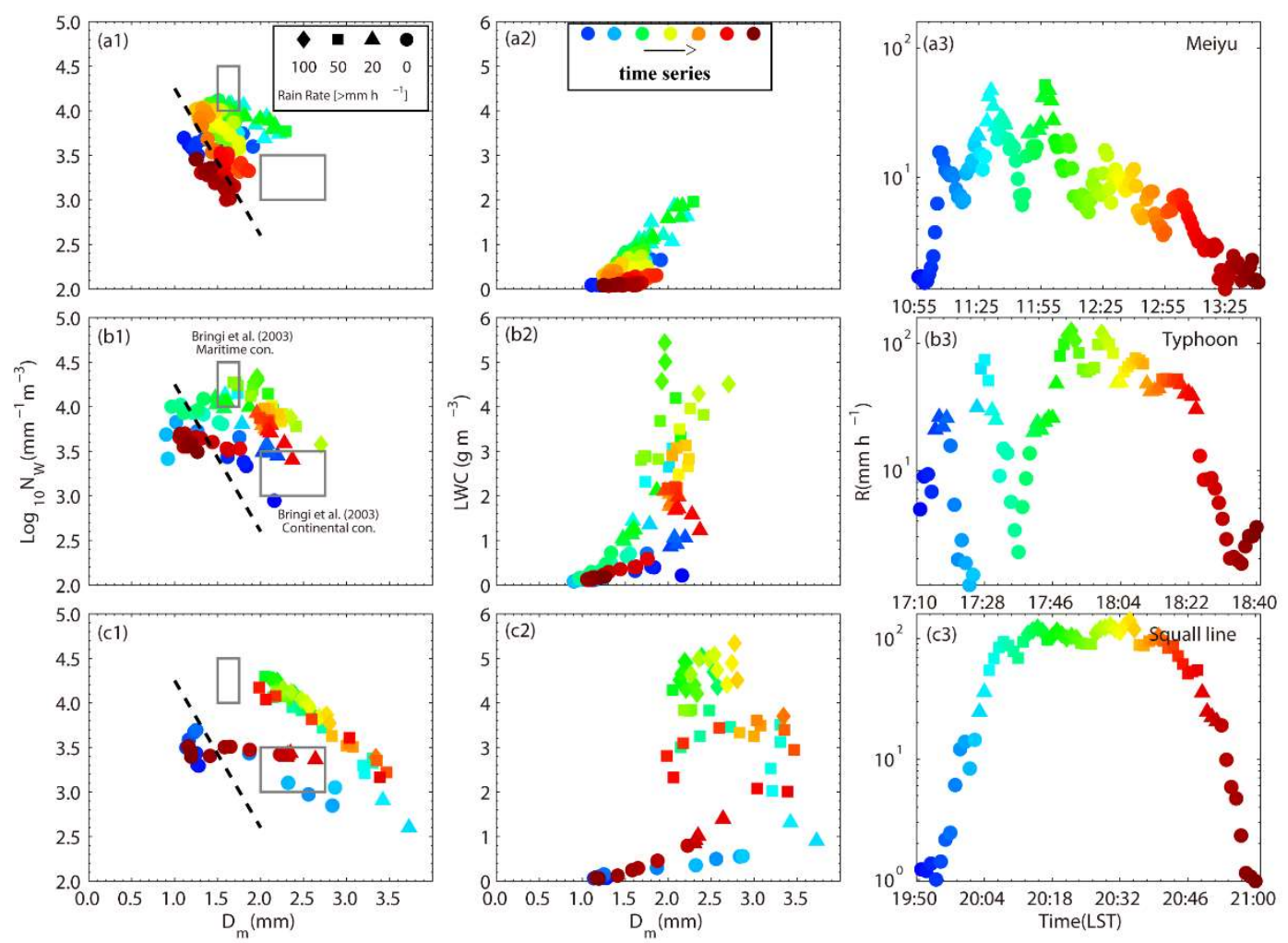

Figure 4. Time series of (a1, b1, and c1) $N_{w}\left(D_{m}\right),(\mathrm{a} 2, \mathrm{~b} 2$, and $\mathrm{c} 2) \operatorname{LWC}\left(D_{m}\right)$, and $(\mathrm{a} 3, \mathrm{~b} 3$, and $\mathrm{c} 3)$ rain rate from: (a) meiyu, (b) typhoon, and (c) squall line, where time increases as the colored markers move from blue to red. Observed samples are shown with four kinds of shapes in different thresholds of rain rate. The two gray rectangles in (a1, b1, and c1) represent the maritime and continental convective clusters, while the black dash line represents the stratiform rain type fitting line, as reported by Bringi et al. [12].

As for the typhoon event (Figure $4 \mathrm{~b})$, the maximum instantaneous rain rate $\left(>100 \mathrm{mmh}^{-1}\right)$ around 17:50 (Figure 4b3) corresponds to a LWC of $5 \mathrm{~g} \mathrm{~m}^{-3}$ (Figure 4b2), the number concentration $\log _{10} \mathrm{~N}_{\mathrm{W}}$ of 4.3 and $a D_{m} \sim 2.0 \mathrm{~mm}$ (Figure $4 \mathrm{~b} 1$ ), close to the characteristics of maritime convection. At the second rainfall peak after 18:00 in (Figure 4b3), the microphysical characteristics move toward the continental convective clusters with $\log _{10} \mathrm{~N}_{\mathrm{w}}$ decreasing to 4 and $\mathrm{D}_{\mathrm{m}}$ exceeding $2.5 \mathrm{~mm}$ (Figure $4 \mathrm{~b} 1$ ). Therefore, high precipitation intensity in the typhoon system can be accompanied by either high value of $N_{w}$ or $\mathrm{D}_{\mathrm{m}}$. The rain rate and LWC on the trailing part of the typhoon rainband decrease rapidly, along with 
the further decrease of $N_{w}$ and $D_{m}$. For the squall line, the initial distribution of $N_{w}$ versus $D_{m}$ locates within the stratiform region (Figure $4 \mathrm{c} 1$ ). Within the convective part of the system, $\mathrm{D}_{\mathrm{m}}$ increases rapidly to $3.5 \mathrm{~mm}$ while $\mathrm{N}_{\mathrm{w}}$ decrease slightly, showing a typical DSD characteristic of continental convection. When $D_{m}$ decreases and $\log _{10} N_{w}$ reaches 4 around the time at 20:12, the instantaneous rain rate exceeds $100 \mathrm{~mm} \mathrm{~h}^{-1}$ (Figure 4c3) and LWC is also peaked (Figure 4c2). The corresponding distribution of $\mathrm{N}_{\mathrm{w}}$ versus $D_{m}$ locates between the maritime and continental convective clusters, similar to the meiyu and typhoon systems, but the mean $\mathrm{D}_{\mathrm{m}}$ is much higher than the other two systems. Beyond the heavy precipitation region, $\mathrm{D}_{\mathrm{m}}$ become smaller and $\mathrm{N}_{\mathrm{w}}$ becomes lower, resulting in a lower LWC.

Results obtained from observations of the OTT-2 indicate that the squall line generally possesses the largest mean size of raindrops during the passage of the rainfall system. And the higher concentration of raindrops in the typhoon and squall line systems correspond to more intense rainfall rate when compared with the meiyu event. On the other hand, the distribution of $\mathrm{N}_{\mathrm{w}}$ versus $\mathrm{D}_{\mathrm{m}}$ can vary widely during the passage of convective systems, sometimes changing the DSD characteristics from continental convective clusters to maritime convective regions (the squall line event). And during the periods with peak instantaneous rain rate and LWC, the DSD characteristics are mainly represented as high $\mathrm{N}_{\mathrm{w}}$ and medium $\mathrm{D}_{\mathrm{m}}$, indicating that heavy precipitation is resulted from a combination of high raindrop concentration and medium raindrops. However, due to the instrument limitation, observed $\mathrm{N}_{\mathrm{w}}\left(\mathrm{D}_{\mathrm{m}}\right)$ from the OTT-2 are lower (higher) than the true values, but the variation and comparison of the DSD characteristics above are basically reliable.

\subsection{Precipitation Features with Radar Observations}

\subsubsection{Vertical Evolution at the OTT-2 Site}

These three convective systems were also observed by the NJU-CPOL in conjunction with the ZM OTT-2. The combined observations are helpful in understanding the microphysical structures and of the precipitation in addition to the DSDs on the ground. The time-height plots of radar variables at the OTT-2 site are illustrated in Figure 5. There is one peak of $Z_{\mathrm{H}}$ and $K_{\mathrm{DP}}$ near the surface in the meiyu event (Figure 5a1, a3), with the values $\sim 45 \mathrm{dBZ}$ and $0.9^{\circ} \mathrm{km}^{-1}$, respectively. And the maximum $Z_{\mathrm{DR}}$ is less than $1.2 \mathrm{~dB}$ during the event. On the other hand, maximum radar reflectivity exceeds $50 \mathrm{dBZ}$ below the $3 \mathrm{~km}$ level in the typhoon system (Figure $5 \mathrm{~b} 1$ ), with the corresponding $Z_{\mathrm{DR}}$ less than $1.4 \mathrm{~dB}$ and the maximum $K_{D P}>3.3^{\circ} \mathrm{km}^{-1}$. High (low) values of $K_{D P}\left(Z_{D R}\right)$ reflect that the typhoon event is mainly composed of small to median raindrops in this layer, while the rainfall rate and LWC are high, consistent with the OTT-2 observations on the ground. As for the squall line event, the maximum $\mathrm{Z}_{\mathrm{H}}$ in the convective core exceeds $55 \mathrm{dBZ}$, indicating the most intense convection among these three events. High $Z_{\mathrm{DR}}$ and $\mathrm{K}_{\mathrm{DP}}$ are also observed, suggesting the existence of large drops and high rain rate. The maximum $Z_{\mathrm{DR}} \sim 3 \mathrm{~dB}$ occurs first around 20:05 at the $3 \mathrm{~km}$ level, and decrease rapidly at 20:14, then the second peak value exists at surface around 20:30, which is consistent with the variation of $D_{m}$ in Figure $4 \mathrm{c} 1$. In addition, the maximum $K_{D P}>4^{\circ} \mathrm{km}^{-1}$ exists at 20:14 at the $4 \mathrm{~km}$ height, then the $K_{\mathrm{DP}}$ core descends to the ground, corresponding to the high rainfall rate at surface (Figure $4 \mathrm{c} 3$ ).

\subsubsection{Composite Vertical Structure of Radar Variables}

To further compare the vertical structures and investigate microphysical processes over the three systems, the contoured frequency by altitude diagrams (CFADs) [44] and mean profiles of $Z_{\mathrm{H}}, Z_{\mathrm{DR}}$, and $\mathrm{K}_{\mathrm{DP}}$ in the convective regions (based on Steiner et al. [45]) around the OTT-2 site are portrayed in Figure 6 . The selected domain of datasets is a $20 \mathrm{~km} \times 20 \mathrm{~km}$ box (gray box in Figure 1) centered on the OTT-2 site, to investigate the precipitation characteristics around the disdrometer. For the convection in the meiyu event, the major distribution (defined as the contoured frequency over $30 \%$ ) of $Z_{\mathrm{H}}$ is between 35 and $47 \mathrm{dBZ}$ near the surface (Figure 6a1). Distributions of $Z_{\mathrm{DR}}$ and $\mathrm{K}_{\mathrm{DP}}$ are relatively narrow with maximum $Z_{\mathrm{DR}}<1.5 \mathrm{~dB}$ and $K_{\mathrm{DP}}<$ than $2^{\circ} \mathrm{km}^{-1}$ located below the freezing level. The $30 \mathrm{dBZ}$ echo top is a proxy of the convective intensity $[46,47]$, while it is basically below the $-10^{\circ} \mathrm{C}$ level for the 
convection in the meiyu system. The downward increase of reflectivity and decrease of $Z_{D R}$ above the $-10{ }^{\circ} \mathrm{C}$ level are evident in the meiyu event, representing the aggregation of ice crystals $[9,48]$. Meanwhile, the increase in $Z_{H}$ and $Z_{D R}$ is also clear around the freezing level, suggesting the melting of aggregates $[9,49,50]$. On the other hand, the major distribution of $Z_{H}$ is between 35 and $51 \mathrm{dBZ}$ near the ground for the typhoon event (Figure $6 \mathrm{~b} 1$ ), the maximum $\mathrm{K}_{\mathrm{DP}}>3^{\circ} \mathrm{km}^{-1}$ and $\mathrm{Z}_{\mathrm{DR}} \sim 2 \mathrm{~dB}$, which reflects more intense convection in the typhoon system when compared to meiyu. In addition, $\mathrm{Z}_{\mathrm{H}}$ and $\mathrm{K}_{\mathrm{DP}}$ increase more rapidly toward the ground below the freezing level in typhoon, indicating the higher efficiency for the growth of LWC through warm-rain processes compared to the meiyu system. The major distribution for the $30 \mathrm{dBZ}$ echo top is around the $-10{ }^{\circ} \mathrm{C}$ level and the processes of aggregation and melting are also evident in the typhoon system, similar to those in the meiyu event.

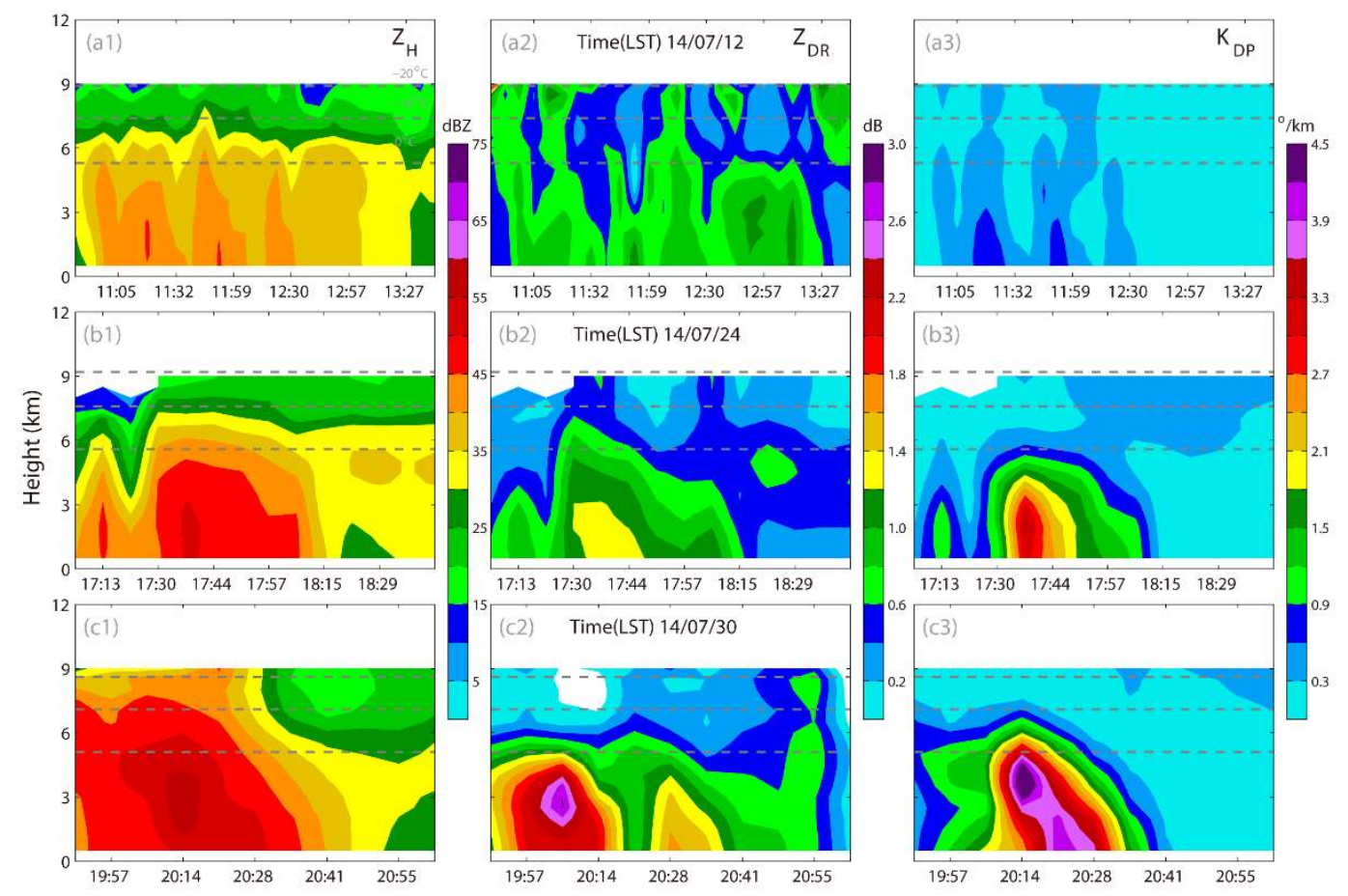

Figure 5. Time-height plots of (a1, b1, and c1) $\mathrm{Z}_{\mathrm{H}},(\mathrm{a} 2, \mathrm{~b} 2$, and $\mathrm{c} 2) \mathrm{Z}_{\mathrm{DR}}$, and (a3, b3, and c3) $\mathrm{K}_{\mathrm{DP}}$ data in (a) meiyu, (b) typhoon and (c) squall line at the position of the $\mathrm{ZM}$ disdormeter. The gray dashed lines indicate the levels of $0{ }^{\circ} \mathrm{C},-10^{\circ} \mathrm{C}$, and $-20^{\circ} \mathrm{C}$ from bottom to top (Table 2), respectively.

For the squall line event, the major distribution of $Z_{\mathrm{H}}$ is between 33 and $54 \mathrm{dBZ}$ at low levels, the maximum frequency near the surface is $\sim 50 \mathrm{dBZ}$, much higher than the other two systems. Maximum values of $Z_{\mathrm{DR}}>3 \mathrm{~dB}$ and $\mathrm{K}_{\mathrm{DP}}>4^{\circ} \mathrm{km}^{-1}$ below the freezing level imply both the existence of large-sized particles and high LWC of raindrops. The major distribution for the $30 \mathrm{dBZ}$ echo top extends $9 \mathrm{~km}$ height and above the $-20^{\circ} \mathrm{C}$ level, which reflects that convection develops much deeper than the other two events. And large amount of high $\mathrm{Z}_{\mathrm{H}}(>30 \mathrm{dBZ})$ and low $\mathrm{Z}_{\mathrm{DR}}(\sim 0 \mathrm{~dB})$ exist between the $-20^{\circ} \mathrm{C}$ and $0{ }^{\circ} \mathrm{C}$ levels, indicating the existence of graupel formed through riming process [9,51].

The vertical profiles of mean $\mathrm{Z}_{\mathrm{H}}, \mathrm{Z}_{\mathrm{DR}}$, and $\mathrm{K}_{\mathrm{DP}}$ are used for the quantitative comparison of the vertical microphysical characteristics among the three systems (Figure 6d1,d2,d3). Firstly, mean $\mathrm{Z}_{\mathrm{H}}$ increase while $\mathrm{Z}_{\mathrm{DR}}$ decrease downwardly above the $-10^{\circ} \mathrm{C}$ level for meiyu and typhoon events. This is consistent with the growth of dendrites and the aggregation of ice crystals at these levels [50]. As for the squall line, convection develops deeper due to a stronger updraft where more water vapor, liquid water and rimed aggregates can be transported into higher levels, producing large irregular ice particles with high (low) value of $Z_{H}\left(Z_{D R}\right)$. $Z_{H}$ and $Z_{D R}$ both increase rapidly downward between the $-10{ }^{\circ} \mathrm{C}$. and $0{ }^{\circ} \mathrm{C}$ levels in all three systems, where riming, aggregation and melting can coexist in this layer and affect the growth of particles $[10,16]$. Below the freezing level, $Z_{H}, Z_{D R}$ and $K_{D P}$ increase 
slowly downward to the surface in the meiyu event, indicating moderate growth of raindrops. In the typhoon event, $Z_{\mathrm{H}}, Z_{\mathrm{DR}}$ and $\mathrm{K}_{\mathrm{DP}}$ increase toward the surface with the mean $\mathrm{K}_{\mathrm{DP}}$ close to $1^{\circ} \mathrm{km}^{-1}$ near the surface, almost doubling that in the meiyu event. The rapid downward increase of these radar variables in conjunction with a high freezing level reflects both the growth of raindrop and LWC through warm-rain processes, which may be a result of the high efficiency of raindrop growth by collision-coalescence and the collection of cloud water in such a moist environment (Figure $2 b$ ). In contrast, $Z_{\mathrm{H}}, Z_{\mathrm{DR}}$ and $\mathrm{K}_{\mathrm{DP}}$ of the squall line rapidly increase downward to the $4 \mathrm{~km}$ level due to the melting of large ice particles like hail or graupel. Then $Z_{\mathrm{DR}}$ continues to increase while $Z_{\mathrm{H}}$ and $\mathrm{K}_{\mathrm{DP}}$ remain constant down to the surface. It may indicate more complex warm-rain processes like the coexistence of size sorting, evaporation and coalescence and needs for further discussion.

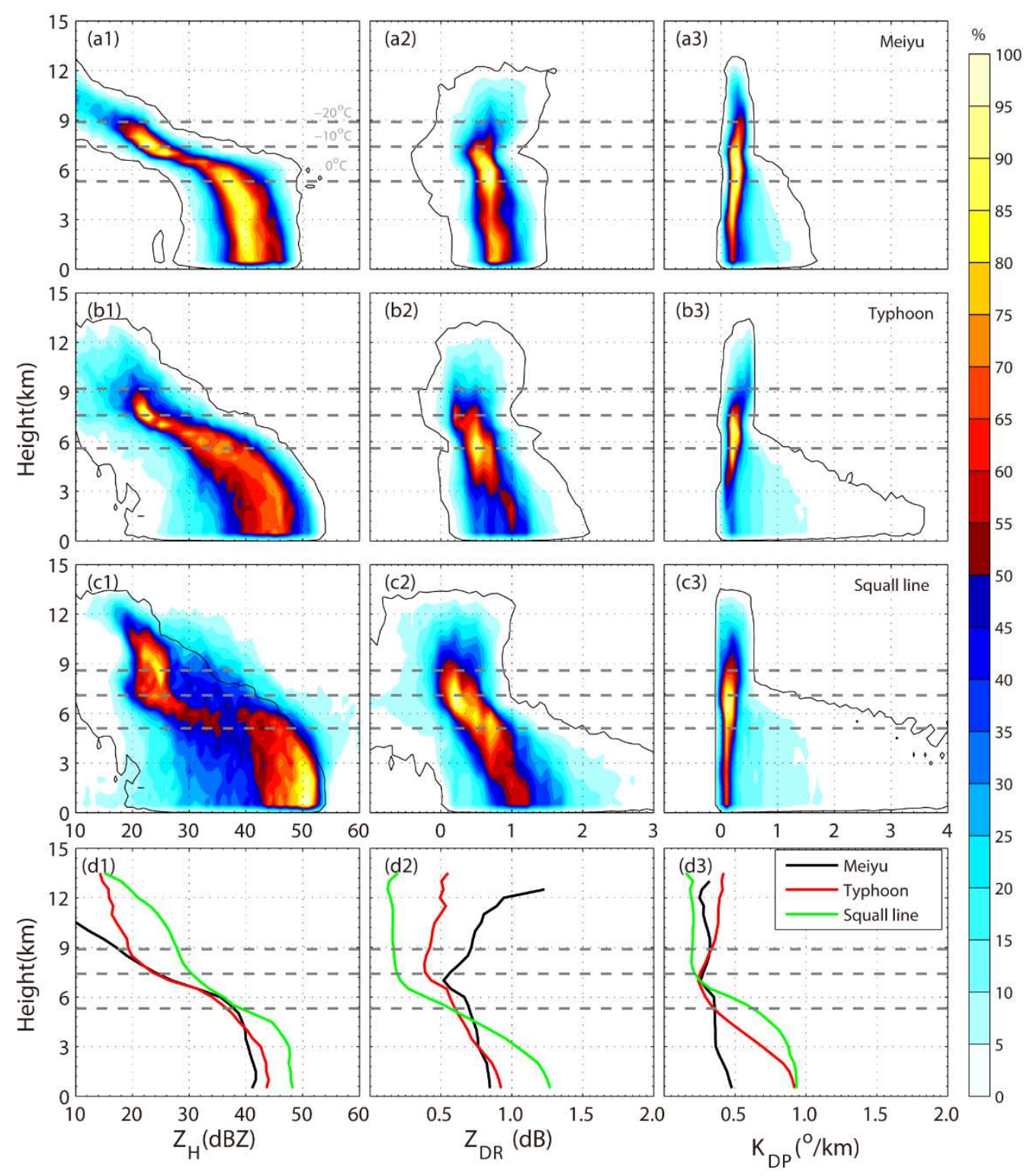

Figure 6. CFADs of convective-only (a1, b1, and c1) $\mathrm{Z}_{\mathrm{H}}$, (a2, b2, and c2) $\mathrm{Z}_{\mathrm{DR}}$, and (a3, b3, and c3) $\mathrm{K}_{\mathrm{DP}}$ data in (a) meiyu, (b) typhoon and (c) squall line. The shaded colors represent the normalized frequency of occurrence relative to the maximum absolute frequency from $5 \%$ to $100 \%$ and the outer black closed curve represent the frequency of $1 \%$. The gray dashed lines indicate the levels of $0{ }^{\circ} \mathrm{C}$, $-10^{\circ} \mathrm{C}$ and $-20^{\circ} \mathrm{C}$ as in Figure 5. The average profiles of the radar variables in the meiyu, typhoon and squall line cases are shown in $\mathrm{d} 1, \mathrm{~d} 2$ and $\mathrm{d} 3$. The CFAD analysis is computed over the domain display in Figure 1 (gray box). 


\subsubsection{HID Results}

The derived HID can be used for further understanding the differences of microphysical characteristics and ice-phase processes like aggregation and riming represented by certain species of ice particles $[9,10]$. The normalized vertical distributions of HID results in all three systems are portrayed in Figure 7. Ice crystals dominate the convective region above the $-20{ }^{\circ} \mathrm{C}$ level in the meiyu event (Figure 7a). A large proportion of aggregates are identified between the $-20^{\circ} \mathrm{C}$ and $-10^{\circ} \mathrm{C}$ levels, indicating increased aggregation of ice crystals. Graupel reaches the $-10^{\circ} \mathrm{C}$ level and the fraction increases downward to the freezing level, indicating active riming process in this layer. Wet snow is an indicator of the melting process [9], and its dominant fraction below the $0{ }^{\circ} \mathrm{C}$ level suggesting the presence of a melting layer. Pure rain is classified at lower heights due to the melting of ice particles. Vertical distribution of hydrometeors in the typhoon event is similar to that of the meiyu event (Figure $7 \mathrm{~b}$ ) except for the higher fraction of aggregates in the upper levels and the presence of graupel at higher altitudes, reflecting more intense convection with a stronger updraft (as shown in Figure $6 \mathrm{a} 1, \mathrm{~b} 1$ ). On the other hand, the presence of hail at the mid-levels of squall line reflects much more active ice-phase processes. Graupel presents above the $12 \mathrm{~km}$ level, where more water vapor, supercooled water and ice particles are transported there by strong updraft. The riming process plays an important role between the $-20{ }^{\circ} \mathrm{C}$ and $0{ }^{\circ} \mathrm{C}$ levels with the fraction of graupel exceeding $40 \%$. Hail melts completely before it reaches the ground (no hail was reported) and big drops are identified with small quantities at low levels, indicating the melting of large ice particles like hail and graupel.

\subsubsection{Inferred Microphysical Processes}

To quantitatively analyze the contributions of ice-phase and warm-rain processes to the surface precipitation among the three systems, separate profiles of ice and liquid water contents are shown in Figure 8. Profiles of the ice water content (IWC) in the meiyu and typhoon events are similar where the maximum values are around $0.25 \mathrm{~g} \mathrm{~m}^{-3}$ at about $6 \mathrm{~km}$ height, similar to that in the North American monsoon convection $[19,48]$ in the mid-latitude. Both meiyu and typhoon events possess maximum LWC $\left(>1.5 \mathrm{~g} \mathrm{~m}^{-3}\right)$ near the surface five times more than the IWCs above the freezing level, indicating the importance of warm-rain processes below the melting layer in these two events. The low-level LWC in the typhoon event $\left(\sim 2.0 \mathrm{~g} \mathrm{~m}^{-3}\right)$ is higher than that in the meiyu event (LWC $1.5 \mathrm{~g} \mathrm{~m}^{-3}$ ), and the faster downwardly increase of LWC represents more efficient raindrop growth from warm-rain processes. A three-fold higher IWC exists above the freezing level in the squall line event when compared with the other two systems, with the maximum value over $0.8 \mathrm{~g} \mathrm{~m}^{-3}$ around $6 \mathrm{~km}$. It indicates more active ice-phase processes and higher production of graupel and hail above the freezing level in the squall line (Figure 7c). On the other hand, convection in the squall line also possesses high LWC $\left(\sim 2.1 \mathrm{~g} \mathrm{~m}^{-3}\right)$ at low levels, the growth of liquid particles is also related to the warm-rain processes in the deep warm cloud layer in this system. Compared to the meiyu and squall line, rainfall at surface from the typhoon event is more dependent on the growth of LWC through efficient warm-rain processes. And regardless of the different environmental conditions (e.g., CAPE and moisture) among the three events, the deep warm cloud layers are always favorable to the development of warm-rain processes.

Since $Z_{\mathrm{H}}$ represents the intensity of precipitation and $Z_{\mathrm{DR}}$ indicates raindrop mean size, the changes in $Z_{H}$ and $Z_{D R}$ over a 3-km layer (0.5-3.5 km AGL) of pure rain is able to reflect the variation of number concentration and size of raindrops, and they are used to infer the dominant warm-rain processes like coalescence, breakup, evaporation and size sorting in recent studies [20,52]. Scatters of $Z_{\mathrm{H}}$ and $Z_{\mathrm{DR}}$ changes from the 3-km pure rain layer over the three systems are plotted in Figure 9, and each dot represents the result derived from one radar volume scan. It shows that the major samples from the typhoon event fall in the coalescence-dominant quadrant (positive $\Delta \mathrm{Z}_{\mathrm{H}}$ and positive $\Delta \mathrm{Z}_{\mathrm{DR}}$ ), indicating the importance of the coalescence process below the melting layer. Samples in the meiyu system are mainly close to the origin with near zero positive $\Delta \mathrm{Z}_{\mathrm{H}}$ and $\Delta \mathrm{Z}_{\mathrm{DR}}$, indicating the warm-rain processes are less active. As for the squall line event, samples with high $\Delta \mathrm{Z}_{\mathrm{DR}}$ and low $\Delta \mathrm{Z}_{\mathrm{H}}$ fall in the coalescence-dominant quadrant, suggesting the slow growth of large-sized raindrops and the 
depletion of smaller particles, since value of $Z_{H}$ is sensitive to the variation of big raindrops, but it is less sensitive to the change of small drops when compared with $Z_{\mathrm{DR}}$. Several samples are also located in the top left quadrant, indicating the non-negligible role of evaporation and size sorting in this convection system, which develops in a relatively dry environment (Table 2). On the other hand, the red (blue) colors of these symbols, which represent the increase (decrease) of the mean LWC values from the higher layer to the lower layer, are also shown in Figure 9. Red symbols are almost located in the coalescence-dominant quadrant, indicating the increase of LWC, which may be related to the raindrop growth by collection of cloud water. While the blue symbols are mainly in the left quadrants, suggesting the decrease of LWC due to the breakup, evaporation and size sorting of the raindrops. The results are consistent with the former analysis using the changes in $\mathrm{Z}_{\mathrm{H}}$ and $\mathrm{Z}_{\mathrm{DR}}$ over the 3-km layer.

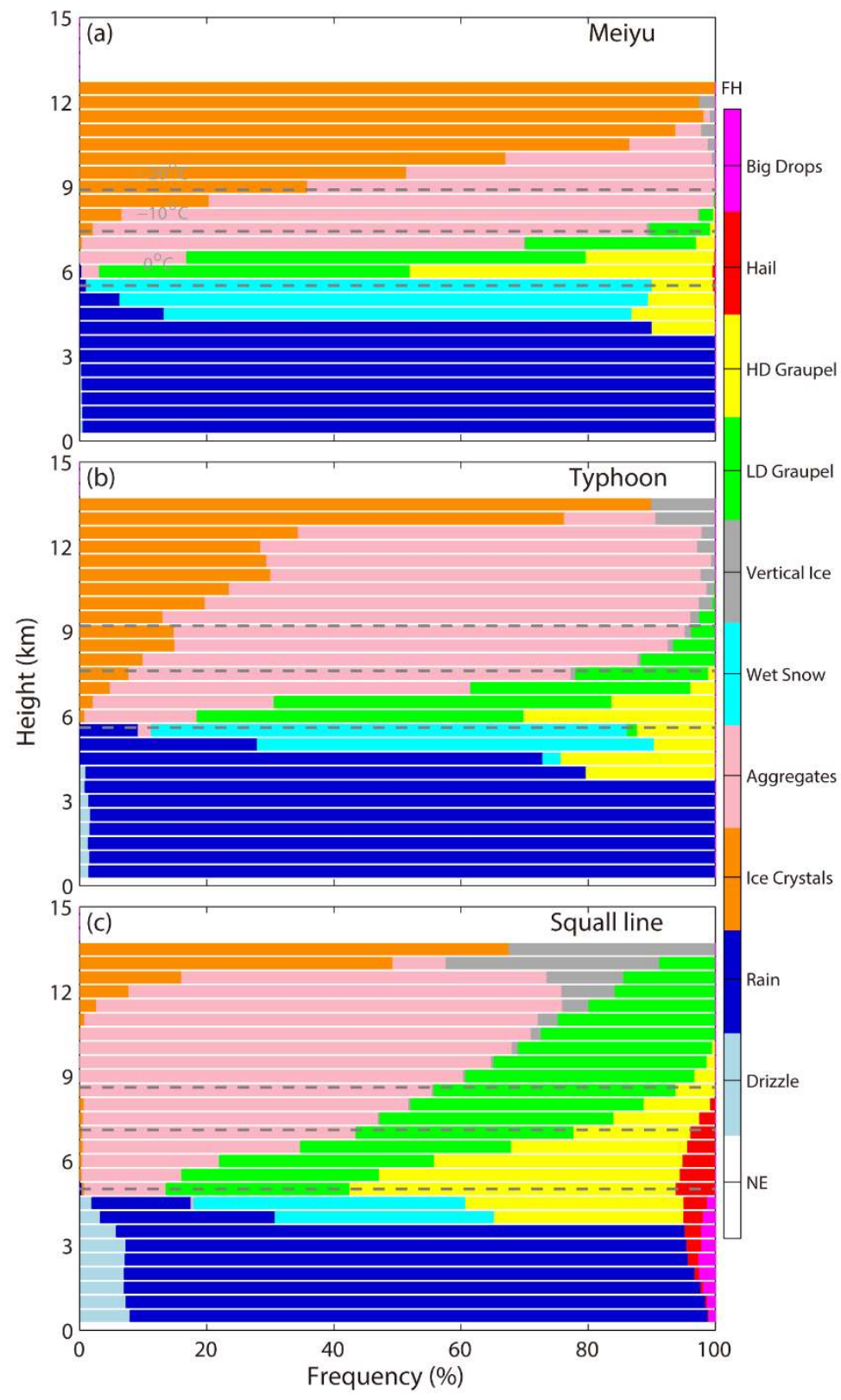

Figure 7. Normalized frequency of occurrence of hydrometeor classification by height $(\mathrm{km})$ in (a) meiyu, (b) typhoon and (c) squall line. Horizontal gray lines indicate the $0{ }^{\circ} \mathrm{C},-10{ }^{\circ} \mathrm{C}$ and $-20^{\circ} \mathrm{C}$ levels, as in Figure 5 . 


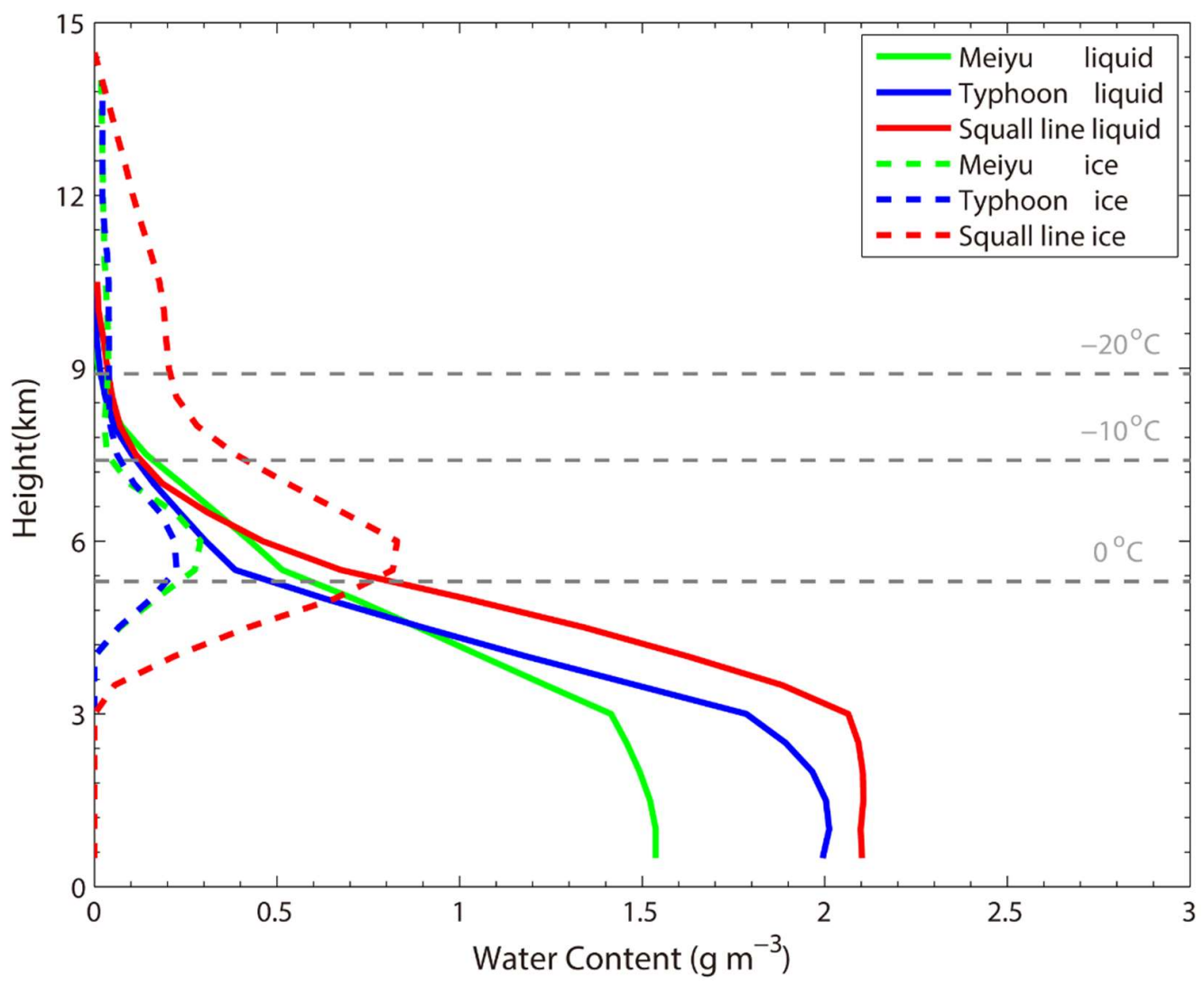

Figure 8. Mean values of liquid (solid lines) water and ice (dashed lines) in the convective region of three precipitation systems.

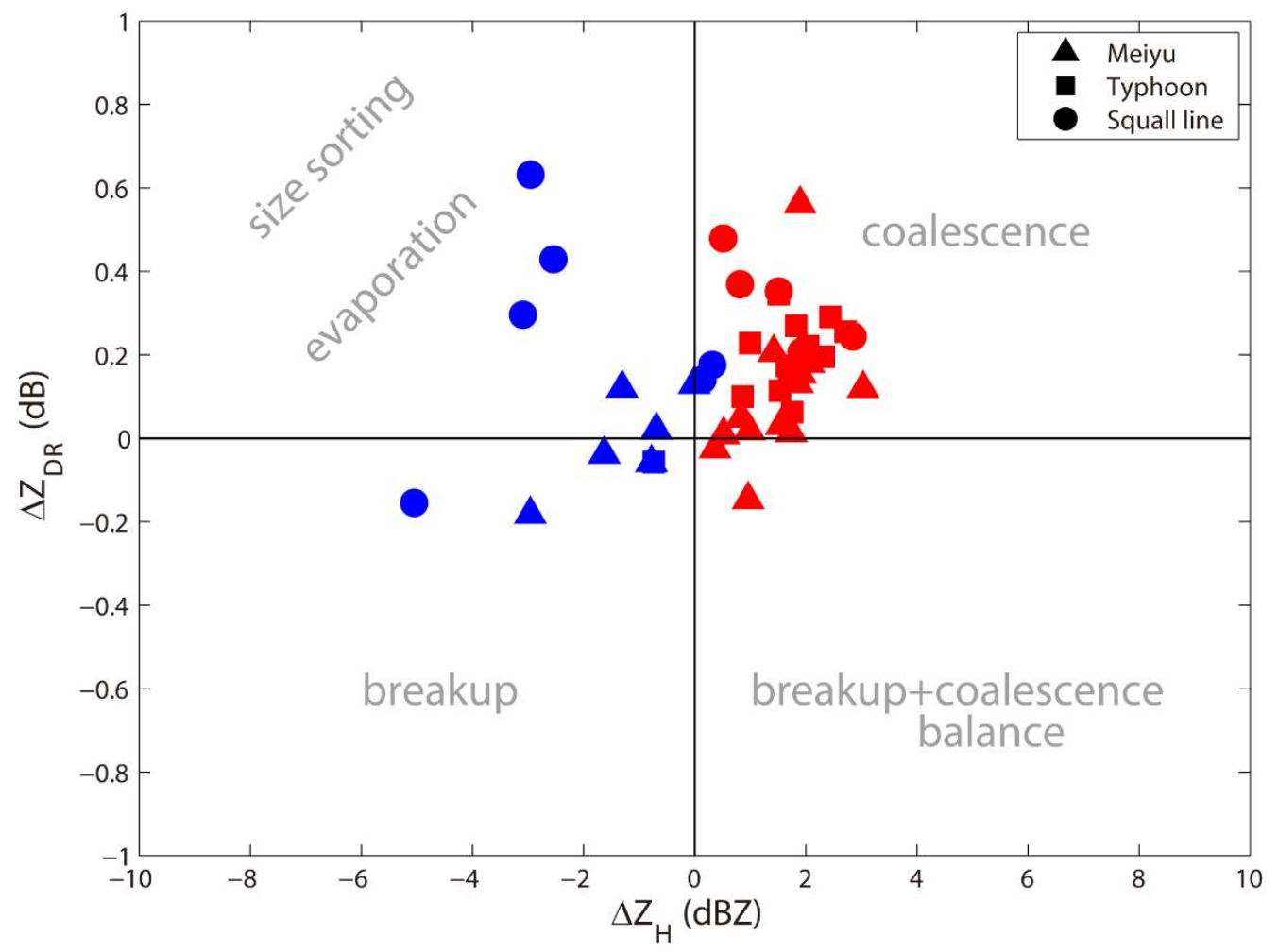

Figure 9. Change in $Z_{D R}$ as a function of the change in $Z_{H}$ over the 3-km rain shaft in the meiyu (triangles), typhoon (squares) and squall line (circles). The microphysical processes represented by 
each quadrant are annotated. The red (blue) colors of these symbols represent the increase (decrease) of the mean LWC values from the higher layer to the lower layer, respectively.

\section{Discussion}

Based on the microphysical analyses above, Figure 10 presents the variation of DSD characteristics

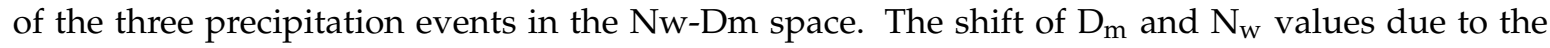
limitation of OTT-2 have been adjusted according to Wen et al. [30]. The colored ellipses depict the distribution of DSDs from the convective regions in the three cases as well as the distribution of DSDs related to heavy precipitation. The surface DSDs are composed of raindrops with relatively high $\mathrm{N}_{\mathrm{W}}$ but small $\mathrm{D}_{\mathrm{m}}$ (blue ellipse) in the convective region of the meiyu event, indicating the overall high number concentration and small mean size of raindrops there. As for the typhoon case, raindrops are generally with slightly larger mean size and even higher number concentration at surface, and the DSD distributions finally shift from the blue ellipse to the green one. On the other hand, the wide distribution of $D_{m}$ and $N_{w}$ in the squall line event (yellow ellipse) suggesting the large variation of DSD characteristics at surface. DSDs distributions of meiyu and typhoon are more close to the maritime convective clusters reported by Bringi et al. [12]. But for the squall line case, it generally locates between the maritime and continental convective clusters. And the surface DSDs with intense rainfall (pink ellipse) are mainly shown the combination of high $\mathrm{N}_{\mathrm{w}}$ and medium $\mathrm{D}_{\mathrm{m}}$, indicating that heavy precipitation is resulted from a combination of high raindrop concentration and medium raindrops.

Our results show that the overall surface DSD distribution of the three precipitation events are closer to the characteristics of warm-rain convection type (group 5 in DO18, dashed orange contour) rather than the ice-based convection type (group 6 in DO18, dashed purple contour). Since the warm-rain (ice-based) convection type of DSD is distinct in the low latitudes (midlatitudes) according to the statistical results of DO18. It indicates that these intense rainfall convections initiated in this midlatitude region of eastern Asia somewhat represent the typical DSD characteristics in low latitudes, suggesting the unique microphysical characteristics here. On the other hand, the ice-based convective DSD features can also be shown in certain periods of the squall line case.

We know that the results of surface DSD characteristics in these precipitation systems should be linked with the vertical microphysical processes and environment conditions. Convections from the meiyu event are in the relatively moist and stable environment, which are relatively shallow but with active warm-rain processes like coalescence. While for the typhoon case, environment is equally stable but with more low-level moisture, convections are intensified at warm cloud layers with higher $\mathrm{Z}_{\mathrm{H}}$ and $K_{\mathrm{DP}}$ due to the growth of raindrop mean size and number concentration via collision-coalescence. As for the squall line event in a drier and more unstable environment, convection develops much deeper, ice-phase processes like aggregation and riming are more active above the freezing level, resulting in higher fraction of graupel and hail. The melting of the large ice particles leads to large raindrops at upper warm cloud layer, while the evaporation and even size-sorting processes can cause low number concentration and high mean size of raindrops at surface in certain periods. On the other hand, the three summertime precipitation events are all with equally deep warm cloud layers, warm-rain processes are essential in determining the potential for intense rainfall. 


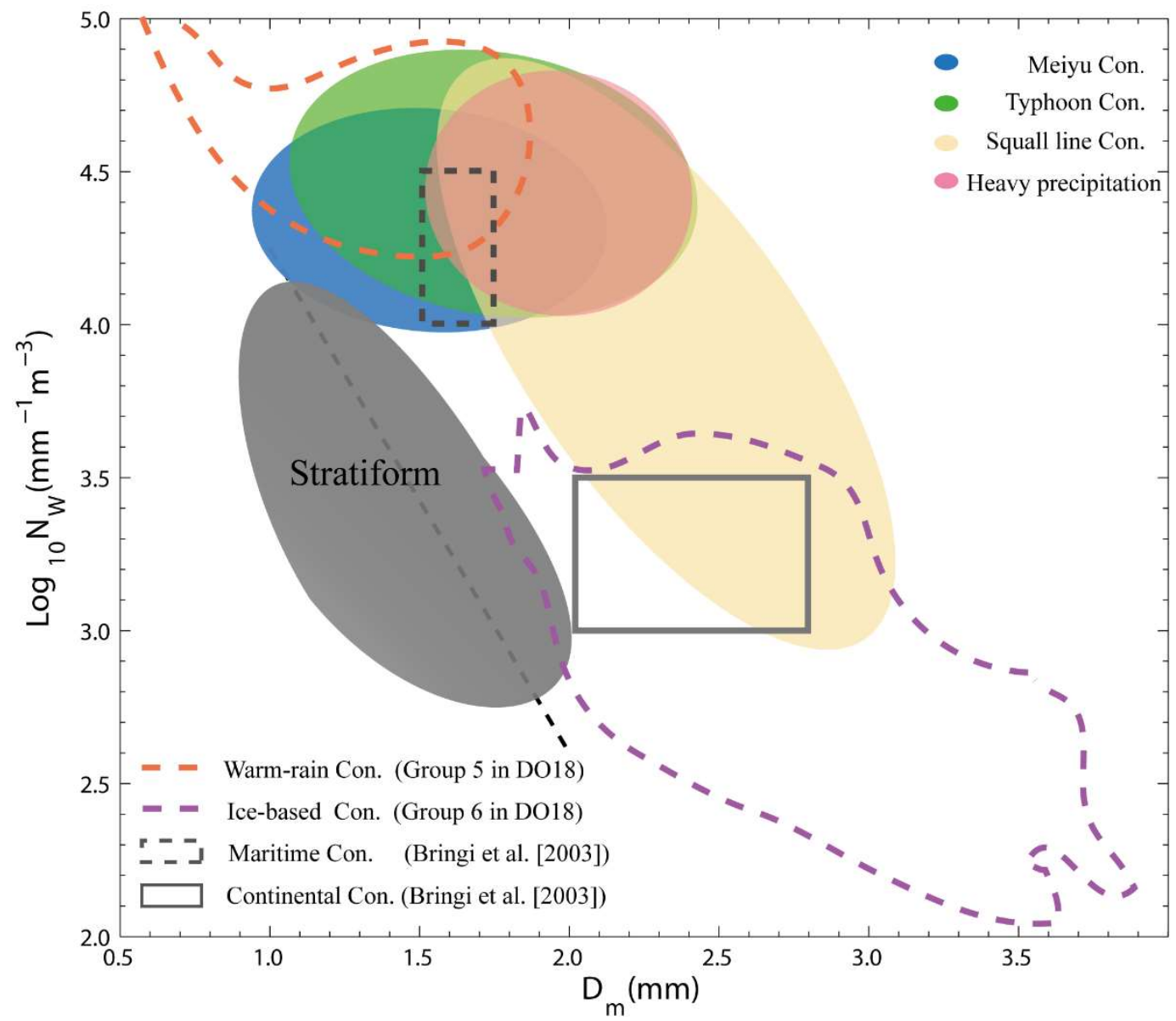

Figure 10. DSD characteristics of the three precipitation events in the $\mathrm{N}_{\mathrm{w}}\left(\mathrm{D}_{\mathrm{m}}\right)$ space. The blue, green and yellow ellipses depict the distribution of DSDs from the convective regions in the meiyu, typhoon and squall line cases, while the pink one shows the distribution of DSDs related to heavy precipitation. Dashed orange and purple contours represents the DSDs from warm-rain convections (group 5) and Ice-based convections (group 6) in DO18, respectively. The two gray rectangles represent the maritime and continental convective clusters in Bringi et al. (2003), while the black dash line represents the stratiform rain type fitting line, the same as in Figure 4. The gray area shows the distribution of DSDs in the stratiform region.

\section{Conclusions}

To describe the microphysical characteristics over different summertime convection systems with intense rainfall in eastern China, data from the combined observations of polarimetric radar and disdrometer during the OPACC field campaign is used in this study. The precipitation structures and DSD characteristics of three precipitation events belonging to different types of convective systems (meiyu rainband, typhoon outer rainband and squall line) are compared. The variation of DSD characteristics in different microphysical processes and environmental conditions are discussed as well.

The characteristics of the raindrop size distribution (DSDs) of these three precipitation systems are compared using data from an OTT-2 disdrometer, while the environmental conditions are presented from the observation of a radiosonde. Results show that the mean raindrop size in the squall line event is larger than the other two cases, indicating the unstable air and a relatively dry environment of this event promotes larger drops at the surface. Nevertheless, short-term extreme rainfall in this convection system is also produced by a large number of smaller raindrops. As for the meiyu and typhoon events in relatively moist environmental conditions, the microphysical characteristics are closer to the maritime precipitation, the number concentrations of surface rainfall DSDs are high while 
the rainfall particles are relatively small. As the increase of moisture in the typhoon environment, values of $D_{m}$ slightly increase and $N_{w}$ are in higher levels, causing higher rainfall intensity.

To further understand the microphysical structures in vertical and their contribution to heavy precipitation at the ground, datasets from the NJU-CPOL polarimetric radar during the passage of the three convection systems over the OTT-2 are selected for the study. Ice-phase processes like aggregation and riming are active in the convection of the squall line event, causing high values of ice water content (IWC) above the freezing level, large proportion of graupel is identified at high levels and hails also exists at the mid-levels, a large number of large raindrops is produced from the melting of the ice particles (graupel and hail), resulting in the rapid increase of $Z_{\mathrm{H}}$ and $Z_{\mathrm{DR}}$. Due to the relatively dry environment at low levels of the squall line event, the warm-rain process of coalescence is somewhat suppressed, notable evaporation of small liquid particles and size sorting also exist below the melting layer, the balance of these warm-rain processes leads to the unchanged of liquid water content downward to the ground. Microphysical features above the freezing level are similar in the meiyu and typhoon events, higher proportion of aggregation exists in the typhoon convection region while the amount of graupel and hail (no hail) is close to the convection in the meiyu event. As for the warm-rain processes, active coalescence of liquid particles helps the rapid increase of liquid water content in the convection of the typhoon event; but for the meiyu convection, liquid water content increases much slower at low levels, it could be attributed to less moisture from the atmospheric environment.

As the extension for the global DSD characteristics of DO18, the variation of surface DSD characteristics over the three events initiated in this midlatitude region of eastern Asia is also summarized in the Nw-Dm diagram. It shows that these intense rainfall convections frequently represent the typical DSD characteristics of warm-rain convective type (group 5 in DO18) in low latitudes, though the ice-based convective DSD features (group 6 in DO18) can also be shown. Co-exist of the two groups of DSDs somewhat suggests that the parameterization of microphysical characteristics in eastern China in numerical models needs to be further investigated to improve rain fall forecast in these heavy rainfall events. The observations of microphysical structures and environment conditions help to further understand this kind of DSD characteristics at surface. Convections from the meiyu and typhoon event are in the relatively moist and stable environment, ice-phase processes are suppressed but warm-rain processes like coalescence are active. While for the squall line event in the drier and more unstable environment, convections develop much deeper and ice-phase processes are more active. The melting of the large ice particles leads to large raindrops at upper warm cloud layer, the evaporation and even size-sorting processes can cause low number concentration and high mean size of raindrops at surface in certain periods. However, all the three summertime precipitation events are with equally deep warm cloud layers, warm-rain processes are always essential in determining the potential for intense rainfall. Limited number of dual-polarization datasets of these heavy rainfall events were collected starting in 2014. Therefore, the microphysical characteristics for the intense precipitation events documented in this study should be considered preliminary. The variation of the DSD characteristics presented in the Nw-Dm diagram may be revised when the available datasets become available.

Supplementary Materials: All datasets used in the study are available at https://pan.baidu.com/s/1lnbxKnP43_FkqU94oBaDQ, password: 5ioz.

Author Contributions: All authors contributed substantially to the research: G.C. and K.Z. conceived and designed the work; L.W., M.W. (Mengyao Wang), H.H., M.W. (Mingjun Wang), Z.Y. helped to collect and analyzed the data; G.Z., P.Z., W.-C.L. provided effective suggestions for the improvement of the manuscript.

Funding: This research was funded by the National Key Research and Development Program of China (grant 2017YFC1501703), the National Natural Science Foundation of China (grants 41475015, 41275031, 41322032, 41905021, 41805015, 41675023), the Open Research Program of the State Key Laboratory of Severe Weather, the Science and Technology Project of Zhejiang Province (2017C03035), and the Key Research Development Program of Jiangsu Science and Technology Department (Social Development Program, No. BE2016732). 
Acknowledgments: The authors acknowledge the field campaign of the National Fundamental Research 973 Program of China (2013CB430101) for providing all the datasets. For more data details, please contact us via email.

Conflicts of Interest: The authors declare no conflict of interest.

\section{References}

1. $\mathrm{Xu}, \mathrm{W}$. Precipitation and Convective Characteristics of Summer Deep Convection over East Asia Observed by TRMM. Mon. Weather Rev. 2013, 141, 1577-1592. [CrossRef]

2. Wen, L.; Zhao, K.; Zhang, G.; Xue, M.; Liu, B.Z.; Chen, X. Statistical Characteristics of Raindrop Size Distributions Observed in East China during the Asian Summer Monsoon Season using 2D-Video Disdrometer and Micro-rain Radar Data. J. Geophys. Res. Atmos. 2016, 121, 2265-2282. [CrossRef]

3. Barnes, H.C.; Houze, R.A. Comparison of observed and simulated spatial patterns of ice microphysical processes in tropical oceanic mesoscale convective systems. J. Geophys. Res. Atmos. 2016, 121, 1-28. [CrossRef]

4. Brown, B.R.; Bell, M.M.; Frambach, A.J. Validation of simulated hurricane drop size distributions using polarimetric radar. Geophys. Res. Lett. 2016, 43, 910-917. [CrossRef]

5. Putnam, B.J.; Xue, M.; Jung, Y.; Snook, N.A.; Zhang, G. Ensemble Probabilistic Prediction of a Mesoscale Convective System and Associated Polarimetric Radar Variables using Single-Moment and Double-Moment Microphysics Schemes and EnKF Radar Data Assimilation. Mon. Weather Rev. 2017, 145, 2257-2279. [CrossRef]

6. Cao, Q.; Zhang, G.; Brandes, E.; Schuur, T.; Ryzhkov, A.; Ikeda, K. Analysis of Video Disdrometer and Polarimetric Radar Data to Characterize Rain Microphysics in Oklahoma. J. Appl. Meteorol. Climatol. 2008, 47, 2238-2255. [CrossRef]

7. $\quad$ Friedrich, K.; Kalina, E.A.; Aikins, J.; Steiner, M.; Gochis, D.; Kucera, P.A.; Ikeda, K.; Sun, J. Raindrop Size Distribution and Rain Characteristics during the 2013 Great Colorado Flood. J. Hydrometeorol. 2015, 17, 53-72. [CrossRef]

8. Chen, B.; Wang, J.; Gong, D. Raindrop Size Distribution in a Midlatitude Continental Squall Line Measured by Thies Optical Disdrometers over East China. J. Appl. Meteorol. Climatol. 2016, 55, 151016095254003. [CrossRef]

9. Barnes, H.C.; Houze, R.A. Precipitation hydrometeor type relative to the mesoscale airflow in mature oceanic deep convection of the Madden-Julian Oscillation. J. Geophys. Res. Atmos. 2015, 119, 13990-14014. [CrossRef]

10. Friedrich, K.; Kalina, E.A.; Aikins, J.; Gochis, D.; Rasmussen, R. Precipitation and cloud structures of intense rain during the 2013 Great Colorado Flood. J. Hydrometeorol. 2016, 17, 27-52. [CrossRef]

11. Lang, T.J.; Rutledge, S.A.; Cifelli, R. Polarimetric radar observations of convection in northwestern Mexico during the North American Monsoon Experiment. J. Hydrometeorol. 2009, 11, 1345-1357. [CrossRef]

12. Bringi, V.N.; Chandrasekar, V.; Hubbert, J.; Gorgucci, E.; Randeu, W.L.; Schoenhuber, M. Raindrop Size Distribution in Different Climatic Regimes from Disdrometer and Dual-Polarized Radar Analysis. J. Atmos. Sci. 2003, 60, 354-365. [CrossRef]

13. Chang, W.Y.; Wang, T.C.; Lin, P.L. Characteristics of the raindrop size distribution and drop shape relation in typhoon systems in the western Pacific from the 2D video disdrometer and NCU C-band polarimetric radar. J. Atmos. Ocean. Technol. 2009, 26, 1973-1993. [CrossRef]

14. Thompson, E.J.; Rutledge, S.A.; Dolan, B.; Thurai, M. Drop Size Distributions and Radar Observations of Convective and Stratiform Rain over the Equatorial Indian and West Pacific Oceans. J. Atmos. Sci. 2015, 72, 4091-4125. [CrossRef]

15. Dolan, B.; Fuchs, B.; Rutledge, S.A.; Barnes, E.A.; Thompson, E.J. Primary modes of global drop-size distributions. J. Atmos. Sci. 2018, 75, 1453-1476. [CrossRef]

16. Wang, M.; Zhao, K.; Xue, M.; Zhang, G.; Liu, S.; Wen, L.; Chen, G. Precipitation microphysics characteristics of a Typhoon Matmo (2014) rainband after landfall over eastern China based on polarimetric radar observations. J. Geophys. Res. Atmos. 2016, 121, 12415-12433. [CrossRef]

17. Wen, J.; Zhao, K.; Huang, H.; Zhou, B.; Yang, Z.; Chen, G.; Wang, M.; Wen, L.; Dai, H.; Xu, L.; et al. Evolution of Microphysical Structure of a Subtropical Squall Line Observed by a Polarimetric Radar and a disdrometer during OPACC in Eastern China. J. Geophys. Res. Atmos. 2017, 122, 8033-8050. [CrossRef]

18. Zhang, G.; Sun, J.; Brandes, E.A. Improving Parameterization of Rain Microphysics with Disdrometer and Radar Observations. J. Atmos. Sci. 2006, 63, 1273-1290. [CrossRef] 
19. Rowe, A.K.; Rutledge, S.A.; Lang, T.J. Investigation of Microphysical Processes Occurring in Organized Convection during NAME. Mon.Weather Rev. 2012, 140, 2168-2187. [CrossRef]

20. Kumjian, M.R.; Prat, O.P. The Impact of Raindrop Collisional Processes on the Polarimetric Radar Variables. J. Atmos. Sci. 2013, 71, 3052-3067. [CrossRef]

21. Luo, Y.; Wu, M.; Ren, F.; Jian, L.; Wong, W.K. Synoptic situations of extreme hourly precipitation over China. J. Clim. 2016, 29, 8703-8719. [CrossRef]

22. Chen, G.; Zhao, K.; Zhang, G.; Huang, H.; Liu, S.; Wen, L.; Yang, Z.; Yang, Z.; Xu, L.; Zhu, W. Improving Polarimetric C-Band Radar Rainfall Estimation with Two-dimensional Video Disdrometer Observations in Eastern China. J. Hydrometeorol. 2017, 18, 1375-1391. [CrossRef]

23. Huang, H.; Zhao, K.; Zhang, G.; Giangrande, S. A Hybrid Method to Estimate Specific Differential Phase and Rainfall with Linear Programming and Physics Constraints. IEEE Trans. Geosci. Remote Sens. 2016, 54, 96-111. [CrossRef]

24. Löffler-Mang, M.; Joss, J. An optical disdrometer for measuring size and velocity of hydrometeors. J. Atmos. Ocean. Technol. 2000, 17, 130-139. [CrossRef]

25. Kruger, A.; Krajewski, W.F. Two-Dimensional Video Disdrometer: A Description. J. Atmos. Ocean. Technol. 2002, 19, 602-617. [CrossRef]

26. Thurai, M.; Bringi, V.N. Drop Axis Ratios from a 2D Video Disdrometer. J. Atmos. Ocean. Technol. 2004, 22, 966-978. [CrossRef]

27. Friedrich, K.; Higgins, S.; Masters, F.J.; Lopez, C.R. Articulating and Stationary PARSIVEL Disdrometer Measurements in Conditions with Strong Winds and Heavy Rainfall. J. Atmos. Ocean. Technol. 2013, 30, 2063-2080. [CrossRef]

28. Battaglia, A.; Rustemeier, E.; Tokay, A.; Blahak, U.; Simmer, C. PARSIVEL snow observations: A critical assessment. J. Atmos. Ocean. Technol. 2010, 27, 333-344. [CrossRef]

29. Tokay, A.; Petersen, W.A.; Gatlin, P.; Wingo, M. Comparison of Raindrop Size Distribution Measurements by Collocated Disdrometers. J. Atmos. Ocean. Technol. 2013, 30, 1672-1690. [CrossRef]

30. Wen, L.; Zhao, K.; Zhang, G.; Liu, S.; Chen, G. Impacts of Instrument Limitations on Estimated Raindrop Size Distribution, Radar Parameters, and Model Microphysics during Mei-Yu Season in East China. J. Atmos. Ocean. Technol. 2017, 34, 1021-1037. [CrossRef]

31. Brandes, E.A.; Zhang, G.; Vivekanandan, J. Experiments in rainfall estimation with a polarimetric radar in a subtropical environment. J. Appl. Meteorol. 2002, 41, 674-685. [CrossRef]

32. Vivekanandan, J.; Ellis, S.M.; Oye, R.; Zrnic, D.S.; Ryzhkov, A.V.; Straka, J. Cloud Microphysics Retrieval Using S-band Dual-Polarization Radar Measurements. Bull. Am. Meteorol. Soc. 1999, 80, 381-388. [CrossRef]

33. Park, H.S.; Ryzhkov, A.; Zrnic, D.; Kim, K.E. The hydrometeor classification algorithm for the polarimetric WSR-88D: Description and application to an MCS. Weather Forecast. 2009, 24, 730-748. [CrossRef]

34. Dolan, B.; Rutledge, S.A.; Lim, S.; Chandrasekar, V.; Thurai, M. A robust C-band hydrometeor identification algorithm and application to a long-term polarimetric radar dataset. J. Appl. Meteorol. Climatol. 2013, 52, 2162-2186. [CrossRef]

35. Rowe, A.K.; Houze, R.A. Microphysical characteristics of MJO convection over the Indian Ocean during DYNAMO. J. Geophys. Res. Atmos. 2014, 119, 2543-2554. [CrossRef]

36. Chang, W.Y.; Lee, W.C.; Liou, Y.C. The Kinematic and Microphysical Characteristics and Associated Precipitation Efficiency of Subtropical Convection during SoWMEX/TiMREX. Mon. Weather Rev. 2015, 143, 317-340. [CrossRef]

37. Carey, L.D.; Rutledge, S.A. The relationship between precipitation and lightning in tropical island convection: A C-band polarimetric radar study. Mon. Weather Rev. 2000, 128, 2687-2710. [CrossRef]

38. Zhang, G.; Vivekanandan, J.; Brandes, E. A method for estimating rain rate and drop size distribution from polarimetric radar measurements. IEEE Trans. Geosci. Remote Sens. 2001, 39, 830-841. [CrossRef]

39. Weisman, M.L.; Klemp, J.B.; Rotunno, R. Structure and Evolution of Numerically Simulated Squall Lines. J. Atmos. Sci. 1988, 45, 1990-2013. [CrossRef]

40. Doswell, C.A., III; Brooks, H.E.; Maddox, R.A. Flash Flood Forecasting: An Ingredients-Based Methodology. Weather Forecast. 1996, 11, 560-581. [CrossRef]

41. Markowski, P.; Richardson, Y. Mesoscale Meteorology in Midlatitudes; John Wiley \& Sons: Hoboken, NJ, USA, 2010. 
42. Gochis, D.; Schumacher, R.; Friedrich, K.; Doesken, N.; Kelsch, M.; Sun, J.; Ikeda, K.; Lindsey, D.; Wood, A.; Dolan, B. The Great Colorado Flood of September 2013. Bull. Am. Meteorol. Soc. 2015, 96, 1461-1487. [CrossRef]

43. Doswell, C.A. Severe convective storms-An overview. Am. Meteor. Soc. 2001, 50, 1-26.

44. Yuter, S.E.; Houze, R.A. Three-Dimensional Kinematic and Microphysical Evolution of Florida Cumulonimbus. Part I: Spatial Distribution of Updrafts, Downdrafts and Precipitation. Mon. Weather Rev. 1995, 123, 1921-1940. [CrossRef]

45. Steiner, M.; Houze, R.A., Jr.; Yuter, S.E. Climatological Characterization of Three-Dimensional Storm Structure from Operational Radar and Rain Gauge Data. J. Appl. Meteorol. 1995, 28, 1978-2007. [CrossRef]

46. DeMott, C.A.; Rutledge, S.A. The vertical structure of TOGA COARE convection. Part I: Radar echo distributions. J. Atmos. Sci. 1998, 55, 2730-2747. [CrossRef]

47. Petersen, W.A.; Rutledge, S.A. Regional variability in tropical convection: Observations from TRMM. J. Clim. 2001, 14, 3566-3586. [CrossRef]

48. Rowe, A.K.; Rutledge, S.A.; Lang, T.J. Investigation of Microphysical Processes Occurring in Isolated Convection during NAME. Mon. Weather Rev. 2011, 139, 424-443. [CrossRef]

49. Andrić, J.; Kumjian, M.R.; Zrnić, D.S.; Straka, J.M.; Melnikov, V.M. Polarimetric Signatures above the Melting Layer in Winter Storms: An Observational and Modeling Study. J. Appl. Meteorol. Climatol. 2013, 52, 682-700. [CrossRef]

50. Schrom, R.S.; Kumjian, M.R. Connecting microphysical processes in Colorado winter storms with vertical profiles of radar observations. J. Appl. Meteorol. Climatol. 2015, 55. [CrossRef]

51. Straka, J.M.; Zrnić, D.S.; Ryzhkov, A.V. Bulk hydrometeor classification and quantification using polarimetric radar data: Synthesis of relations. J. Appl. Meteorol. 2000, 39, 1341-1372. [CrossRef]

52. Carr, N.; Kirstetter, P.E.; Gourley, J.J.; Hong, Y. Polarimetric Signatures of MidLatitude Warm-Rain Precipitation Events. J. Appl. Meteorol. Climatol. 2017, 56, 697-711. [CrossRef]

(C) 2019 by the authors. Licensee MDPI, Basel, Switzerland. This article is an open access article distributed under the terms and conditions of the Creative Commons Attribution (CC BY) license (http://creativecommons.org/licenses/by/4.0/). 